\title{
Effects of thermal buoyancy and variable thermal conductivity on the MHD flow and heat transfer in a power-law fluid past a vertical stretching sheet in the presence of a non-uniform heat source
}

\author{
M. Subhas Abel ${ }^{a, *}$, P.G. Siddheshwar ${ }^{\mathrm{b}}$, N. Mahesha ${ }^{\mathrm{a}}$ \\ ${ }^{a}$ Department of Mathematics, Gulbarga University, Gulbarga, Karnataka, India \\ ${ }^{\mathrm{b}}$ Department of Mathematics, Bangalore University, Bangalore, Karnataka, India
}

\section{A R T I C L E I N F O}

\section{Article history:}

Received 1 May 2008

Received in revised form 1 August 2008

Accepted 5 August 2008

\section{Keywords:}

Power-law fluid

Stretching sheet

Variable thermal conductivity

Non-uniform heat source

Prandtl number

Grashof number

\begin{abstract}
A B S T R A C T
The paper considers the flow of a power-law fluid past a vertical stretching sheet. Effects of variable thermal conductivity and non-uniform heat source/sink on the heat transfer are addressed. The thermal conductivity is assumed to vary linearly with temperature. Similarity transformation is used to convert the governing partial differential equations into a set of coupled, non-linear ordinary differential equations. Two different types of boundary heating are considered, namely Prescribed power-law Surface Temperature (PST) and Prescribed power-law Heat Flux (PHF). Shooting method is used to obtain the numerical solution for the resulting boundary value problems. The effects of Chandrasekhar number, Grashof number, Prandtl number, non-uniform heat source/sink parameters, wall temperature parameter and variable thermal conductivity parameter on the dynamics are shown graphically in several plots. The skin friction and heat transfer coefficients are tabulated for a range of values of the parameters. Present study reveals that in a gravity affected flow buoyancy effect has a significant say in the control of flow and heat transfer.
\end{abstract} (c) 2008 Elsevier Ltd. All rights reserved.

\section{Introduction}

The study of laminar boundary layer flow and heat transfer in non-Newtonian fluids past a stretching sheet has gained tremendous interest amongst researchers for the past two decades because of its industrial and engineering applications. The problem has scientific and engineering applications such as aerodynamic extrusion of plastic sheets and fibers, drawing, annealing and tinning of copper wire, paper production, crystal growing and glass blowing. Such applications involve cooling of a molten liquid by drawing it into a cooling system. In drawing the liquid into the cooling system it is sometimes stretched as in the case of a polymer extrusion process. The fluid mechanical properties desired for the outcome of such a process depends mainly on the rate of cooling and the stretching rate. It is important that a proper cooling liquid is chosen and flow of the cooling liquid due to the stretching sheet is controlled so as to arrive at the desired properties for the outcome. As a result, one has to pay considerable attention in knowing both flow and heat transfer characteristics of the cooling fluid.

\footnotetext{
* Corresponding author. Tel.: +919886467609.

E-mail address: msabel2001@yahoo.co.uk (M.S. Abel).
}

In view of such applications Crane [1] initiated the analytical study of boundary layer flow due to a stretching sheet. He assumed the velocity of the sheet to vary linearly as the distance from the slit and arrived at an analytical solution. The work of Crane was subsequently extended by many authors to both Newtonian and non-Newtonian boundary layer flows with various velocity and thermal boundary conditions; see Refs. [2-29]. Gupta and Gupta [2] investigated heat transfer from an isothermal stretching sheet with suction/blowing effects. Chen and Char [3] extended the works of Gupta and Gupta [2] to that of a non-isothermal stretching sheet. Grubka and Bobba [4] carried out heat transfer studies by considering the power-law variation of surface temperature. Chiam [5] investigated the magnetohydrodynamic heat transfer over a non-isothermal stretching sheet.

In the available literature, constant physical properties are considered for the cooling liquid. Most of the practical situations demand for physical properties with variable characteristics. The material properties such as viscosity and thermal conductivity are prone to vary with a temperature gradient, especially in the boundary layer region. With this view point, Chiam [6,7] considered the effect of variable thermal conductivity on heat transfer assuming it to vary linearly with the temperature.

Heat source/sink effects are crucial in controlling the heat transfer. Many of the authors have studied heat transfer by considering 
a uniform heat source/sink, i.e., a temperature-dependent heat source/sink (see [8]). Eldahab and El-Aziz [9] included the effect of non-uniform heat source/sink (space- and temperature-dependent heat source/sink) on the heat transfer.

These investigations deal with the flow and heat transfer induced by a horizontal stretching sheet, but there arise some situations where the stretching sheet moves vertically in the cooling liquid (see Fig. 1). Under such circumstances the fluid flow and the heat transfer characteristics are determined by two mechanisms, namely the motion of stretching sheet and the buoyant force. The thermal buoyancy resulting from heating/cooling of a vertically moving stretching sheet has a large impact on the flow and heat transfer characteristics. Effects of thermal buoyancy on the flow and heat transfer under various physical situations have been reported by many investigators (see [10-14]). Recently, Partha et al. [15] studied mixed convection heat transfer from an exponentially stretching sheet.

Mention can be made that these studies concern boundary layer behavior of only Newtonian fluids over horizontal/vertical stretching sheet. However, most of the practical situations demand for fluids that are non-Newtonian in nature which are abundantly used in many industrial and engineering applications. This called for the study of boundary layer behavior over a stretching sheet in nonNewtonian fluids. Andersson et al. [16] studied the magnetohydrodynamic flow of a power-law fluid over a stretching sheet. Hassanien et al. [17] investigated the flow and heat transfer in a power-law fluid over a non-isothermal stretching sheet with suction/injection. An excellent work on magnetohydrodynamic stretching sheet problem on power-law fluid has been reported by Liao [18] using the homotopy based analytical method. Cortell [19] studied the magnetohydrodynamic flow of a power-law fluid over a stretching sheet. There are also studies concerning viscoelastic fluid reported by Rajagopal [20], Siddheshwar and Mahabaleshwar [21], Cortell [22], Andersson [23], Abel et al. [24-26] and references therein. In addition to the above papers on linear stretching there are some excellent recent papers on non-linear stretching (see [27-29] and references therein). The authors are presently investigating this aspect of the problem in power-law liquids.

A close observation of the literature reveals that there are some missing links, i.e., there are studies which do not consider variable fluid properties or non-uniform heat source/sink effects. Even if they are taken into account they are restricted to the case of Newtonian fluids only (see the following table):

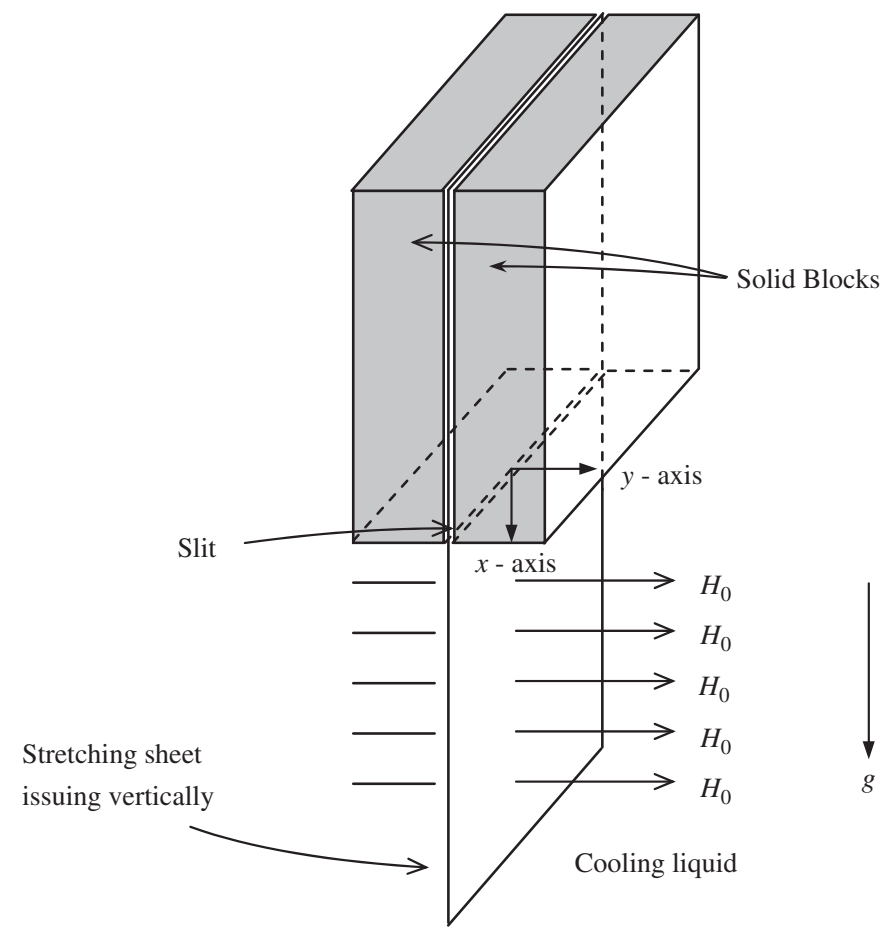

Fig. 1. Schematic of polymer extrusion process under the influence of gravity.

the same for investigation. We adopt two different types of boundary conditions for heat transfer analysis, namely the prescribed surface temperature condition (PST) and the prescribed surface heat flux condition (PHF).

\section{Mathematical formulation}

We consider the steady two-dimensional flow of an incompressible, weak electrically conducting power-law fluid past an impermeable vertical stretching sheet. The flow is generated by the action of two equal and opposite forces along the $x$-axis and $y$-axis being normal to the flow. The sheet is stretched with a velocity $u_{w}(x)$ which is proportional to the distance from the origin (Fig. 2) and it is

\begin{tabular}{|c|c|c|c|c|}
\hline Author & Fluid considered & Stretching & Thermal conductivity & Heat source/sink \\
\hline Chiam [7] & Newtonian & Horizontal & Variable & - \\
\hline Vajravelu and Rollins [8] & Newtonian & Horizontal & Constant & Uniform \\
\hline Abo-Eldahab and Aziz [9] & Newtonian & Inclined & Constant & Non-uniform \\
\hline Vajravelu and Nayfeh [10] & Newtonian & Vertical & Constant & Uniform \\
\hline Gorla et al. [11] & Newtonian & Vertical & Constant & - \\
\hline Chen [12] & Newtonian & Vertical & Constant & - \\
\hline Chen [13] & Newtonian & Inclined & Constant & - \\
\hline Ahmed [14] & Newtonian & Vertical & Constant & - \\
\hline Partha et al. [15] & Newtonian & Vertical & Constant & - \\
\hline Andersson et al. [16] & Non-Newtonian & Horizontal & - & - \\
\hline Hassanien et al. [17] & Non-Newtonian & Horizontal & Constant & - \\
\hline Cortell $[22]$ & Non-Newtonian & Horizontal & Constant & - \\
\hline Abel et al. [24] & Non-Newtonian & Horizontal & Constant & Non-uniform \\
\hline Abel and Mahesha [25] & Non-Newtonian & Horizontal & Variable & Non-uniform \\
\hline
\end{tabular}

The present paper attempts to fill this lacuna. To the best of authors' knowledge, so far no one has considered the flow and heat transfer in a power-law fluid due to a vertical stretching sheet in the presence of an external magnetic field, non-uniform heat source/sink and variable thermal conductivity. This fact motivated us to propose assumed to be warmer than the ambient fluid, i.e., $t_{w}(x)>t_{\infty}$. The flow field is further subjected to a transverse uniform magnetic field of strength $H_{0}$ (along $y$-axis).

The boundary layer equations governing the flow and heat transfer in a power-law fluid over a vertical stretching sheet, assuming 


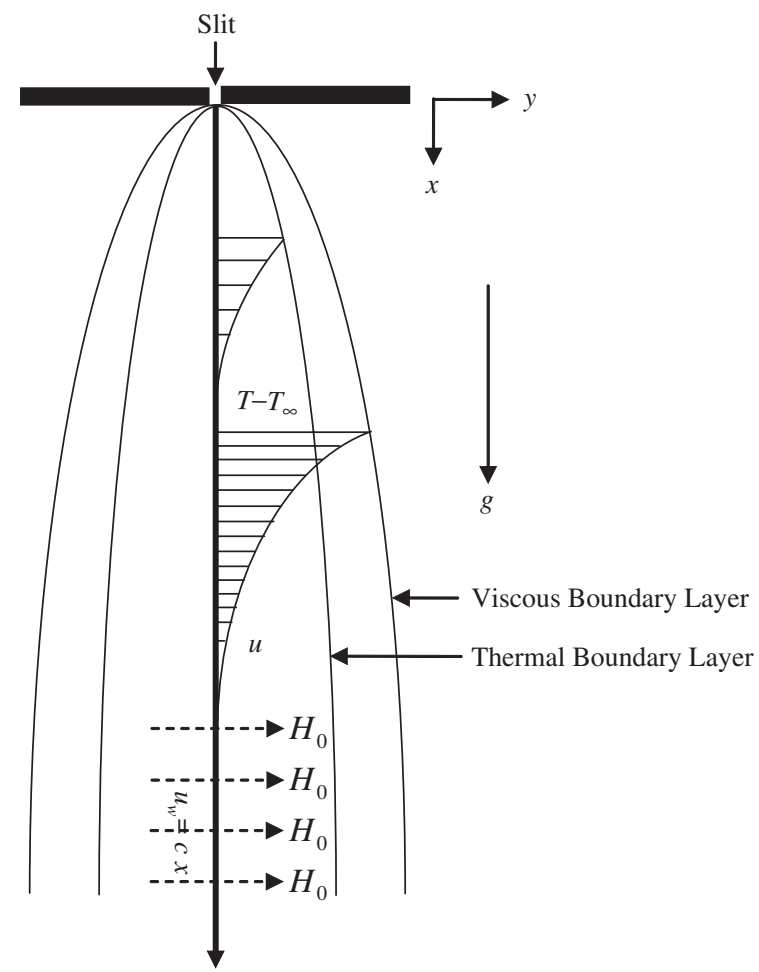

Stretching Sheet

Fig. 2. Schematic of boundary layers induced by a vertical stretching sheet.

that the viscous dissipation is negligible, are

$\frac{\partial u}{\partial x}+\frac{\partial v}{\partial y}=0$

$u \frac{\partial u}{\partial x}+v \frac{\partial u}{\partial y}=\frac{1}{\rho} \frac{\partial \tau_{x y}}{\partial y}-\frac{\sigma H_{0}^{2} u}{\rho}+g \beta_{0}\left(t-t_{\infty}\right)$

$u \frac{\partial t}{\partial x}+v \frac{\partial t}{\partial y}=\frac{\partial}{\partial y}\left(\frac{k(t)}{\rho C_{p}} \frac{\partial t}{\partial y}\right)+\frac{q^{\prime \prime \prime}}{\rho C_{p}}$,

where $u$ and $v$ are the velocity components along $x$ and $y$ directions, respectively, $t$ is the temperature of the fluid, $\rho$ is the density, $\sigma$ is the electrical conductivity of the fluid, $\beta_{0}$ is the thermal expansion coefficient, $C_{p}$ is the specific heat at constant pressure.

Following the two-parameter power-law model of Ostwald-de Waele the shear stress $\tau_{x y}$ appearing in Eq. (2) can be written as (see [30]):

$\tau_{x y}=K\left|\frac{\partial u}{\partial y}\right|^{n-1} \frac{\partial u}{\partial y}$

where $K$ is the consistency coefficient and $n$ is the power-law index. The above power-law model represents Newtonian fluid when $n=1$, with the dynamic coefficient of viscosity $K$. If $n<1$ the model represents shear thinning fluids (pseudo-plastic) and if $n>1$ the model represents shear thickening fluids (dilatant).

The thermal conductivity $k(t)$ is assumed to vary linearly with temperature in the form

$k(t)=k_{\infty}\left[1+\frac{\varepsilon}{\Delta t}\left(t-t_{\infty}\right)\right]$

where $k_{\infty}$ is the thermal conductivity of the liquid far away from the sheet, $\Delta t=t_{w}-t_{\infty}$ is the sheet-fluid temperature difference and $\varepsilon$ is a small parameter. We note that $\varepsilon$ is scalar and signifies variation of the thermal conductivity with temperature. If the above expression is viewed as a truncated Taylor's series expansion then $\varepsilon=\left.\left(\Delta t / k_{\infty}\right)(\partial k / \partial t)\right|_{t=t_{\infty}}$.

The non-uniform heat source/sink $q^{\prime \prime \prime}$ is modeled as (see [9])

$q^{\prime \prime \prime}=\frac{\rho k u_{w}(x)}{x K}\left[A^{*}\left(t_{w}-t_{\infty}\right) f^{\prime}+\left(t-t_{\infty}\right) B^{*}\right]$,

where $A^{*}$ and $B^{*}$ are the coefficients of space- and temperaturedependent heat source/sink, respectively. Here we make a note that the case $A^{*}>0, B^{*}>0$ corresponds to internal heat generation and that $A^{*}<0, B^{*}<0$ corresponds to internal heat absorption.

We have adopted the following boundary conditions:

$u=u_{w}=c x, \quad v=0,\left\{\begin{array}{ll}t=t_{w}=t_{\infty}+A\left(\frac{x}{L}\right)^{\lambda} & \text { in PST } \\ -k \frac{\partial t}{\partial y}=q_{w}=D\left(\frac{x}{L}\right)^{\lambda+((1-n) /(1+n))} & \text { in PHF }\end{array}\right\}$

at $y=0$,

$u \rightarrow 0, \quad t \rightarrow t_{\infty} \quad$ as $y \rightarrow \infty$,

where $t_{w}$ is the temperature of the sheet, $t_{\infty}$ is the temperature of the fluid far away from the sheet, $A$ and $D$ are positive constants, $\lambda$ is the temperature parameter and $L$ is the characteristic length.

We introduce the following dimensionless variables:

$X=\frac{x}{L}, \quad Y=\left(\frac{\rho U_{0}^{2-n} L^{n}}{K}\right)^{1 /(n+1)} \frac{y}{L}, \quad U=\frac{u}{U_{0}}$,

$V=\left(\frac{\rho U_{0}^{2-n} L^{n}}{K}\right)^{1 /(n+1)} \frac{v}{U_{0}}$

$T=\frac{t-t_{\infty}}{t_{w}-t_{\infty}}, \quad \tau_{X Y}=\left|\frac{\partial U}{\partial Y}\right|^{n-1} \frac{\partial U}{\partial Y}=\left(\frac{K U_{0}^{3 n} \rho^{n}}{L^{n}}\right)^{-1 /(n+1)} \tau_{x y}$,

$\operatorname{Re}_{L}=\frac{\rho U_{0}^{2-n} L^{n}}{K}$,

where $U_{0}=c L$ is the reference velocity and

$t_{w}-t_{\infty}=\left\{\begin{array}{ll}A\left(\frac{x}{L}\right)^{\lambda} & \text { in PST } \\ \frac{D L R e_{L}^{-1 /(n+1)}}{k_{\infty}}\left(\frac{x}{L}\right)^{\lambda} & \text { in PHF }\end{array}\right\}$.

The boundary layer equations (1)-(3) now take the following form:

$\frac{\partial U}{\partial X}+\frac{\partial V}{\partial Y}=0$

$U \frac{\partial U}{\partial X}+V \frac{\partial U}{\partial Y}=\frac{\partial}{\partial Y}\left(\left|\frac{\partial U}{\partial Y}\right|^{n-1} \frac{\partial U}{\partial Y}\right)-Q U+G r_{L} T$,

$U \frac{\partial T}{\partial X}+V \frac{\partial T}{\partial Y}+\frac{\lambda T U}{X}=\frac{1}{P r_{L}}\left\{(1+\varepsilon T) \frac{\partial^{2} T}{\partial Y^{2}}+\varepsilon\left(\frac{\partial T}{\partial Y}\right)^{2}\right\}$

$$
+(1+\varepsilon T)\left(\alpha f^{\prime}+\beta T\right)
$$

where $Q=\sigma H_{0}^{2} / \rho c$ is the Chandrasekhar number, $\operatorname{Pr}_{L}=\rho C_{p} U_{0} L /$ $k_{\infty}\left(R e_{L}\right)^{2 /(n+1)}$ is the uniform Prandtl number, $R e_{L}=\rho U_{0}^{2-n} L^{n} / K$ is the uniform Reynolds number, $G r_{L}=g \beta_{0}\left(t_{w}-t_{\infty}\right) / c^{2} L$ is the uniform Grashof number, $\alpha=k_{\infty} A^{*} / K C_{p}$ is the space-dependent heat source/sink parameter and $\beta=k_{\infty} B^{*} / K C_{p}$ is the temperaturedependent heat source/sink parameter.

The boundary conditions given in (7) take the form

$U=U_{W}=X, V=0, \quad\left\{\begin{array}{ll}\frac{\partial}{\partial T} 1 & \text { in PST } \\ \frac{\partial}{Y}=\frac{-1}{(1+\varepsilon)} X^{(1-n) /(1+n)} & \text { in PHF }\end{array}\right\}$ at $Y=0$,
$U \rightarrow 0, \quad T \rightarrow 0$ as $Y \rightarrow \infty$. 
Introducing the stream function $\psi(X, Y)$ so as to satisfy the continuity equation in the dimensionless form (8), we may write

$U=\frac{\partial \psi}{\partial Y}, \quad V=-\frac{\partial \psi}{\partial X}$.

Using (12), Eqs. (9) and (10) can be written as

$$
\begin{aligned}
& \frac{\partial \psi}{\partial Y} \frac{\partial^{2} \psi}{\partial X \partial Y}-\frac{\partial \psi}{\partial X} \frac{\partial^{2} \psi}{\partial Y^{2}}=\frac{\partial}{\partial Y}\left(\left|\frac{\partial^{2} \psi}{\partial Y^{2}}\right|^{n-1} \frac{\partial^{2} \psi}{\partial Y^{2}}\right)-Q \frac{\partial \psi}{\partial Y}+G r_{L} T \\
& \frac{\partial \psi}{\partial Y} \frac{\partial T}{\partial X}-\frac{\partial \psi}{\partial X} \frac{\partial T}{\partial Y}+\frac{\lambda T}{X} \frac{\partial \psi}{\partial Y}=\frac{1}{\operatorname{Pr}_{L}}\left\{(1+\varepsilon T) \frac{\partial^{2} T}{\partial Y^{2}}+\varepsilon\left(\frac{\partial T}{\partial Y}\right)^{2}\right\} \\
& +(1+\varepsilon T)\left(\alpha f^{\prime}+\beta T\right) \text {. }
\end{aligned}
$$

Corresponding boundary conditions in (11) take the form:

$$
\begin{aligned}
& \frac{\partial \psi}{\partial Y}=X, \quad \frac{\partial \psi}{\partial X}=0, \quad\left\{\begin{array}{ll}
\frac{T}{\partial T} 1 & \text { in PST } \\
\frac{\partial Y}{(1+\varepsilon)} X^{(1-n) /(1+n)} & \text { in PHF }
\end{array}\right\} \text { at } Y=0, \\
& \frac{\partial \psi}{\partial Y} \rightarrow 0, \quad T \rightarrow 0 \quad \text { as } Y \rightarrow \infty \text {. }
\end{aligned}
$$

In order to convert the partial differential equations (13) and (14) into ordinary differential equations the following similarity transformation is used:

$\psi(X, Y)=X^{2 n /(n+1)} f(\eta), \quad T(X, Y)=\left\{\begin{array}{ll}\theta(\eta) & \text { in PST } \\ g(\eta) & \text { in PHF }\end{array}\right\}$,

$\eta=X^{(1-n) /(1+n)} Y$.

Using (16), Eq. (13) can be written as

$n\left(-f^{\prime \prime}\right)^{n-1} f^{\prime \prime \prime}-f^{\prime 2}+\left(\frac{2 n}{n+1}\right) f f^{\prime \prime}-Q f^{\prime}+G r_{x} \theta=0$,

where the prime denotes differentiation with respect to the similarity variable $\eta$. In writing Eq. (17) it is assumed that for the flow next to stretching surface $\partial u / \partial y \leqslant 0$, i.e., $f^{\prime \prime} \leqslant 0$.

Correspondingly the boundary conditions in (15) for velocity take the form:

$f(\eta)=0, \quad f^{\prime}(\eta)=1 \quad$ at $\eta=0$,

$f^{\prime}(\eta) \rightarrow 0$ as $\eta \rightarrow \infty$.

Again using (16) in Eqs. (14) and (15) we get

(i) PST:

$$
\begin{aligned}
& (1+\varepsilon \theta) \theta^{\prime \prime}+\operatorname{Pr}_{x}\left\{\left(\frac{2 n}{n+1}\right) f \theta^{\prime}-\lambda f^{\prime} \theta\right\} \\
& \quad+\operatorname{Pr}_{x}(1+\varepsilon \theta)\left(\alpha f^{\prime}+\beta \theta\right)+\varepsilon \theta^{2}=0, \\
& \theta(\eta)=1 \text { at } \eta=0 \\
& \theta(\eta) \rightarrow 0 \text { as } \eta \rightarrow \infty
\end{aligned}
$$

(ii) PHF:

$$
\begin{aligned}
& (1+\varepsilon g) g^{\prime \prime}+\operatorname{Pr}_{x}\left\{\left(\frac{2 n}{n+1}\right) f g^{\prime}-\lambda f^{\prime} g\right\} \\
& \quad+\operatorname{Pr}_{x}(1+\varepsilon g)\left(\alpha f^{\prime}+\beta g\right)+\varepsilon g^{\prime 2}=0, \\
& g^{\prime}(\eta)=\frac{-1}{1+\varepsilon} \text { at } \eta=0, \\
& g(\eta) \rightarrow 0 \text { as } \eta \rightarrow \infty .
\end{aligned}
$$

The dimensionless numbers $G r_{x}=g \beta_{0}\left(t_{w}-t_{\infty}\right) / c^{2} x$ and $P r_{x}=$ $\rho C_{p} u_{w} x / k_{\infty}\left(R e_{x}\right)^{2 /(n+1)}$ appearing in the final boundary layer equations (17), (19) and (21) are, respectively, the local Grashof number and local Prandtl numbers and $R e_{x}=\rho u_{w}^{2-n} x^{n} / K$ is the local Reynolds number. From the analysis reported in this section it is clear that we are adopting local similarity in our study and hence the appearance of local Prandtl and Grashof numbers. For simplicity the subscript $x$ is dropped when referring to these local dimensionless numbers in Section 4 and 5 . The local skin friction coefficient $C_{\mathrm{f}}$ is given by

$C_{\mathrm{f}}=-2 R e_{x}^{-1 /(n+1)}\left[-f^{\prime \prime}(0)\right]^{n}$.

In the PST case we are fixing the surface temperature and hence we calculate the local heat flux as follows:

$q_{w}=-\frac{(1+\varepsilon)\left(t_{w}-t_{\infty}\right) R e_{x}^{1 /(n+1)}}{x} \theta^{\prime}(0)$.

In the PHF case we are fixing the surface heat flux and hence we compute the surface temperature as follows:

$t_{w}-t_{\infty}=\frac{D L}{k_{\infty}} \operatorname{Re}_{L}^{-1 /(n+1)}\left(\frac{x}{L}\right)^{\lambda} g(0)$.

We now outline the procedure for solving the boundary value problems (19) and (20) and (21) and (22) which are coupled with (17) and (18).

\section{Method of solution}

We adopt the most effective shooting method (see Refs. [31,32]) with fourth order Runge-Kutta integration scheme to solve the boundary value problems in PST and PHF cases mentioned in the previous section. The coupled non-linear equations (17) and (19) in the PST case are transformed into a system of five first order differential equations as follows:

$$
\begin{aligned}
\frac{\mathrm{d} f_{0}}{\mathrm{~d} \eta} & =f_{1}, \\
\frac{\mathrm{d} f_{1}}{\mathrm{~d} \eta} & =f_{2}, \\
\frac{\mathrm{d} f_{2}}{\mathrm{~d} \eta} & =\frac{1}{n}\left(-f_{2}\right)^{1-n}\left\{f_{1}^{2}-\left(\frac{2 n}{n+1}\right) f_{0} f_{2}+Q f_{1}-G r_{x} \theta_{0}\right\}, \\
\frac{\mathrm{d} \theta_{0}}{\mathrm{~d} \eta} & =\theta_{1}, \\
\frac{\mathrm{d} \theta_{1}}{\mathrm{~d} \eta} & =\frac{1}{1+\varepsilon \theta_{0}}\left\{\lambda r_{x} f_{1} \theta_{0}-\left(\frac{2 n}{n+1}\right) \operatorname{Pr}_{x} f_{0} \theta_{1}-\varepsilon \theta_{1}^{2}\right\}-\operatorname{Pr}_{X}\left(\alpha f_{1}+\beta \theta_{0}\right) .
\end{aligned}
$$
form

Subsequently the boundary conditions in (18) and (20) take the $f_{0}(0)=0, \quad f_{1}(0)=1, \quad f_{1}(\infty)=0$,

$\theta_{0}(0)=1, \quad \theta_{0}(\infty)=0$.

Here $f_{0}=f(\eta)$ and $\theta_{0}=\theta(\eta)$. Aforementioned boundary value problem is converted to an initial value problem by choosing the values of $f_{2}(0)$ and $\theta_{1}(0)$ appropriately. Resulting initial value problem is integrated using the fourth order Runge-Kutta method. Newton-Raphson method is implemented to correct the guess values of $f_{2}(0)$ and $\theta_{1}(0)$. In solving Eqs. (26) subjected to boundary conditions (27) the appropriate ' $\infty$ ' is determined through actual computation. It differs for each set of parameter values. Same procedure is adopted to solve the boundary layer equations (17) and (21) subjected to conditions (18) and (22) in the PHF case. The results are presented in several tables and graphs.

\section{Results and discussion}

MHD boundary layer flow and heat transfer in a weak electrically conducting power-law fluid past a vertical stretching sheet 
a

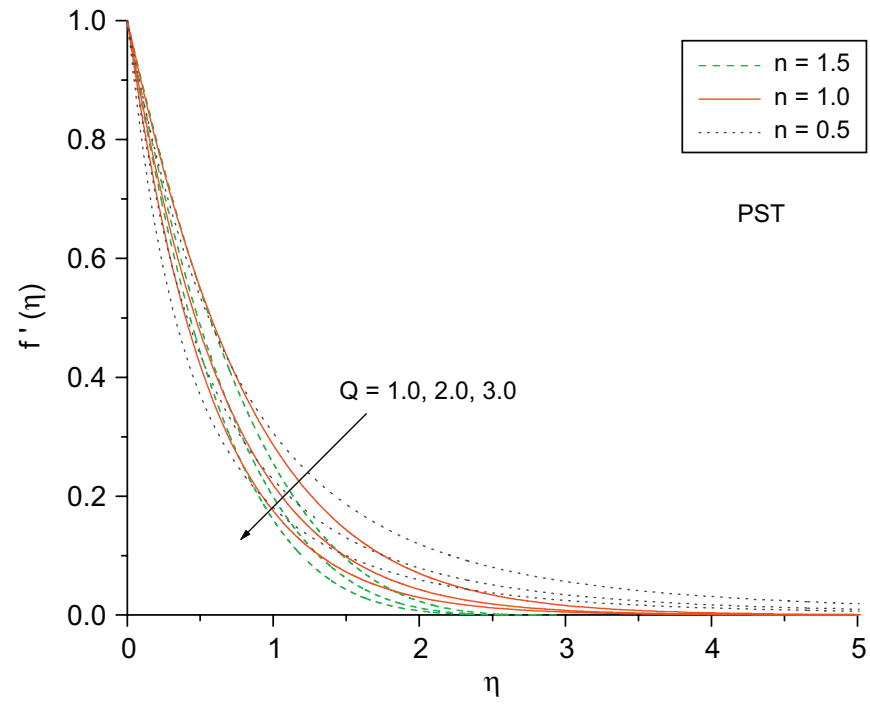

b

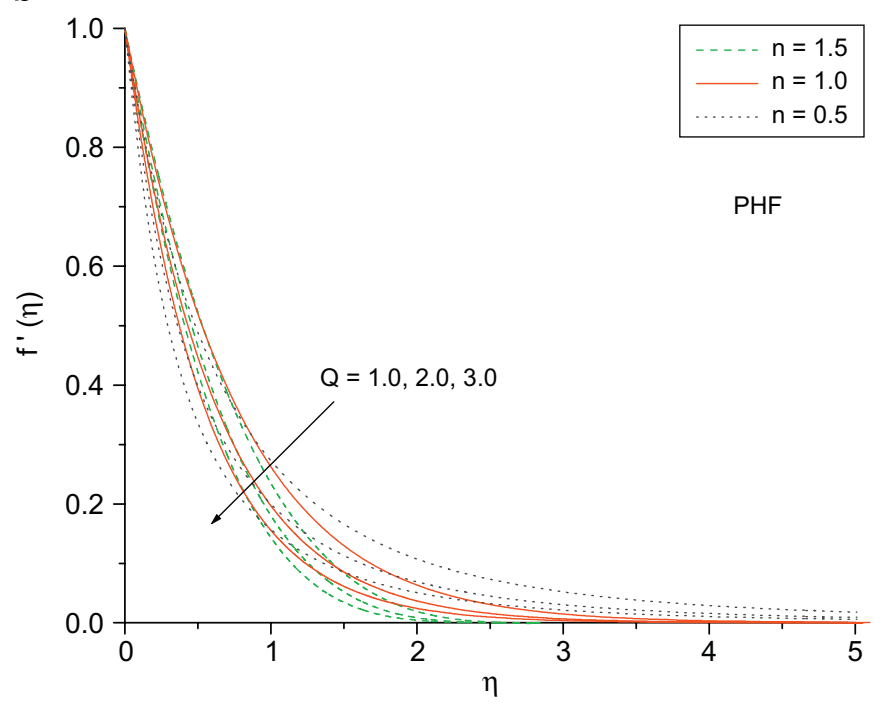

Fig. 3. Effect of Chandrasekhar number $Q$ on horizontal velocity profiles with $G r=1.0, \operatorname{Pr}=3.0, \alpha=-0.05, \beta=-0.05, \lambda=1.0$ and $\varepsilon=0.1$.

a

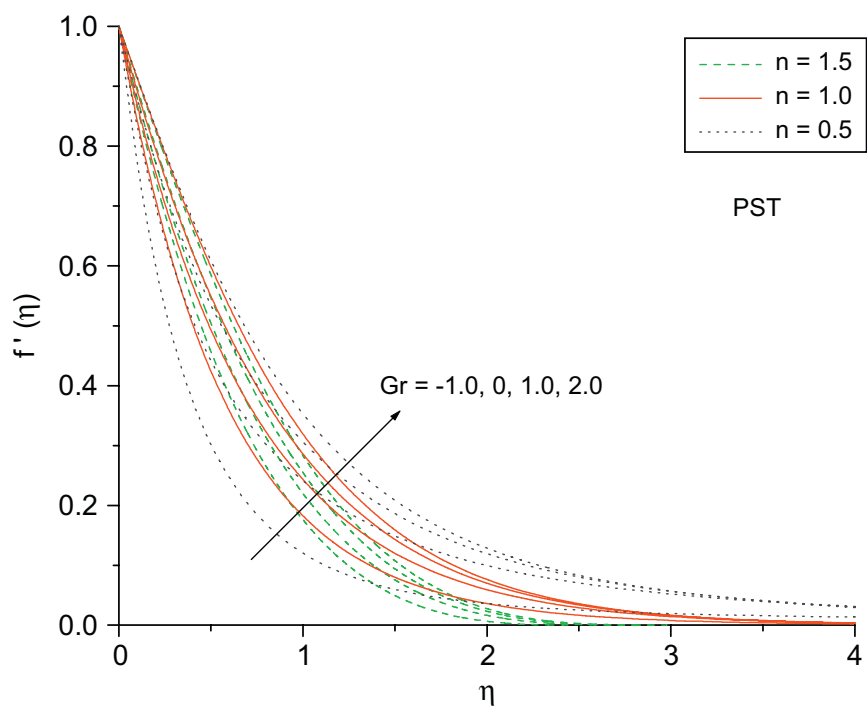

b

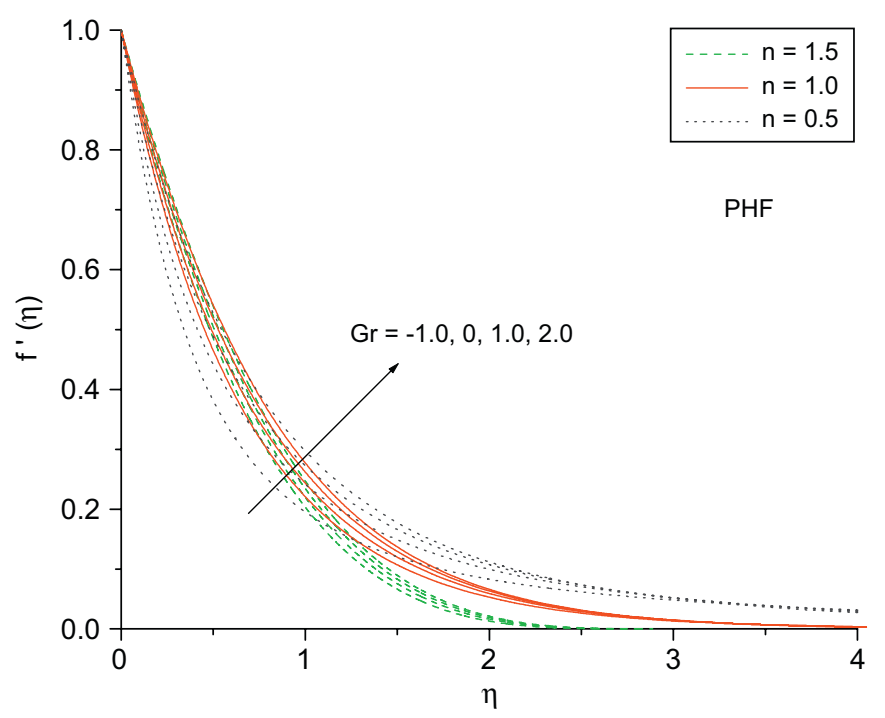

Fig. 4. Effect of Grashof number $G r$ on horizontal velocity profiles with $Q=1.0, \operatorname{Pr}=3.0, \alpha=-0.05, \beta=-0.05, \lambda=1.0$ and $\varepsilon=0.1$.

with variable thermal conductivity is investigated in the presence of non-uniform heat source/sink. Numerical solution of the problem is obtained by shooting method. The effect of $Q, \operatorname{Pr}, G r, \alpha, \beta, \varepsilon$ and $\lambda$ on flow and heat transfer is shown graphically in Figs. 3-16.

Before we move on to the discussion of the results obtained, we note that a weak electrically conducting fluid is considered for the investigation. Mazola corn oil is an example for such a fluid having weak electrical conductivity (see [33] and the references therein for other details):

$\sigma(T)=\left[0.21+0.03\left(T-10^{\circ}\right)\right] \times 10^{-10} \mathrm{mho} / \mathrm{m}$.

Clearly with respect to this weak electrically conducting fluid, $\sigma$ is very small and hence we have followed Hartmann formulation for the present study.

Fig. 3 shows the effect of Chandrasekhar number $Q$ on the horizontal velocity profiles $f^{\prime}(\eta)$ for PST and PHF cases. From these plots it is evident that increasing values of $Q$ results in flattening of $f^{\prime}(\eta)$.
The transverse contraction of the velocity boundary layer is due to the applied magnetic field which results in the Lorentz force producing considerable opposition to the motion. The effect of flattening of $f^{\prime}(\eta)$ as a consequence of increasing the strength of magnetic field is observed in all the three types of fluids namely, pseudo-plastic, Newtonian and dilatant fluids.

The Grashof number Gr highlights the significance of convection in controlling the axial velocity. The effect of $\mathrm{Gr}$ on the horizontal velocity profiles is shown in Fig. 4 for the cases of PST and PHF. These plots indicate that the momentum boundary layer thickness increases with increasing value of $\mathrm{Gr}$ enabling more flow. The buoyancy force evolved as a consequence of cooling of the vertical stretching sheet acts like a favorable pressure gradient accelerating the fluid in the boundary layer region. Effect of $\mathrm{Gr}$ is analogous in all three types of fluids. Here, we make a note that for $G r=0$, one can obtain the results of horizontal stretching sheet problem. 
a

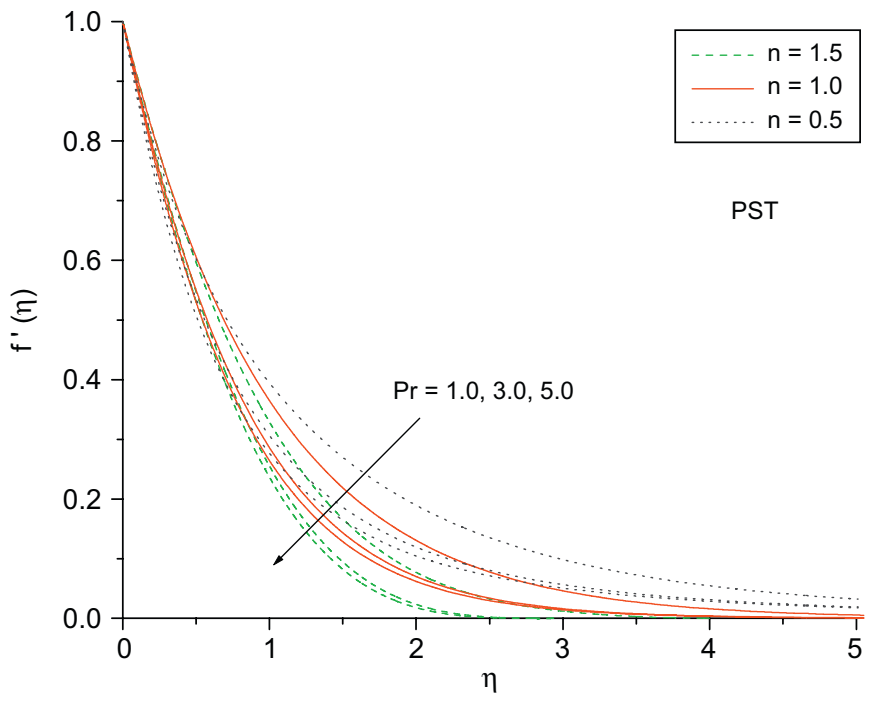

b

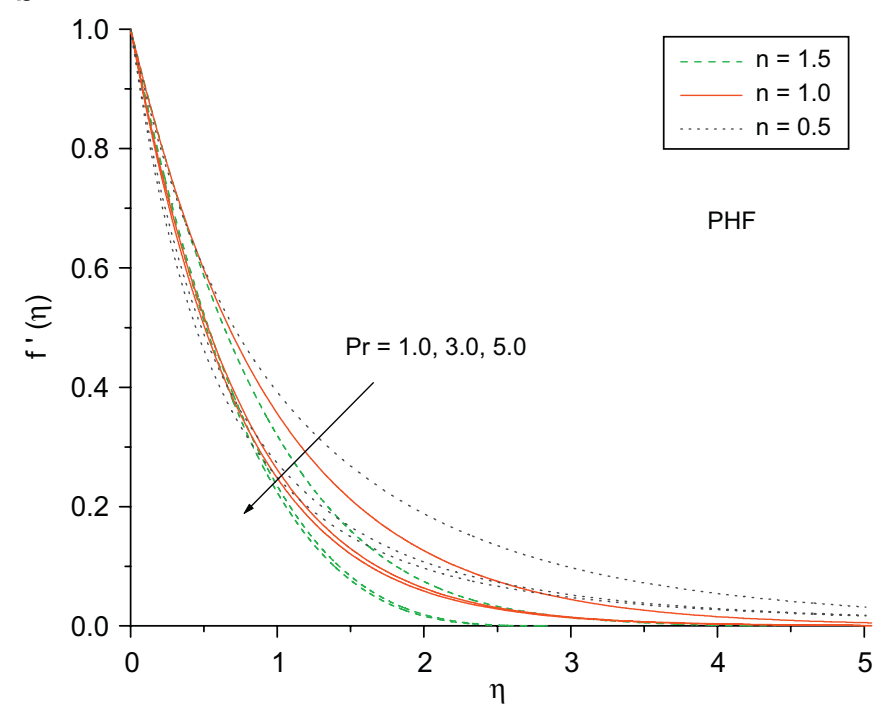

Fig. 5. Effect of Prandtl number $\operatorname{Pr}$ on horizontal velocity profiles with $Q=1.0, G r=1.0, \alpha=-0.05, \beta=-0.05, \lambda=1.0$ and $\varepsilon=0.1$.

a

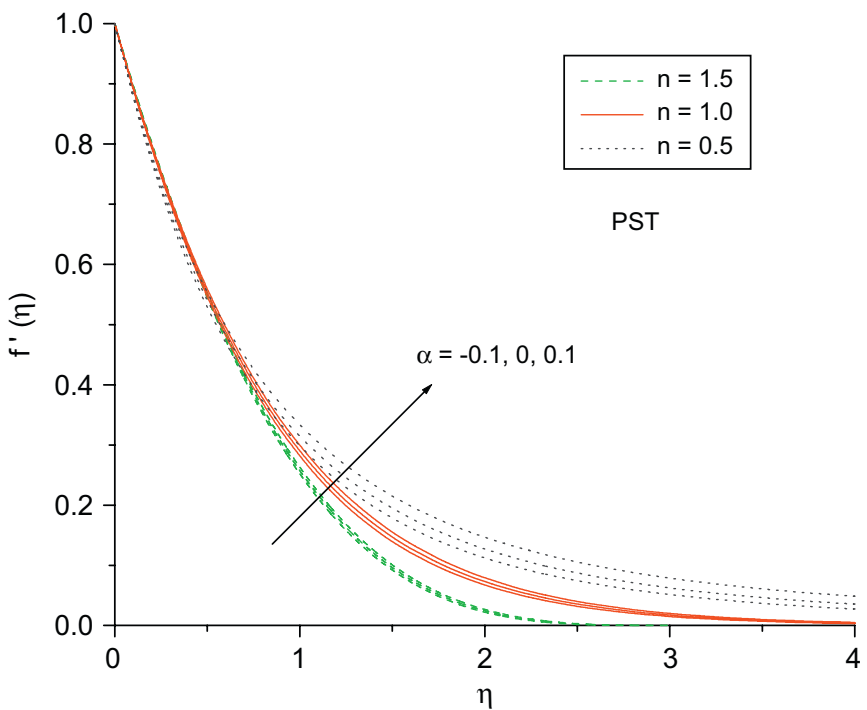

b

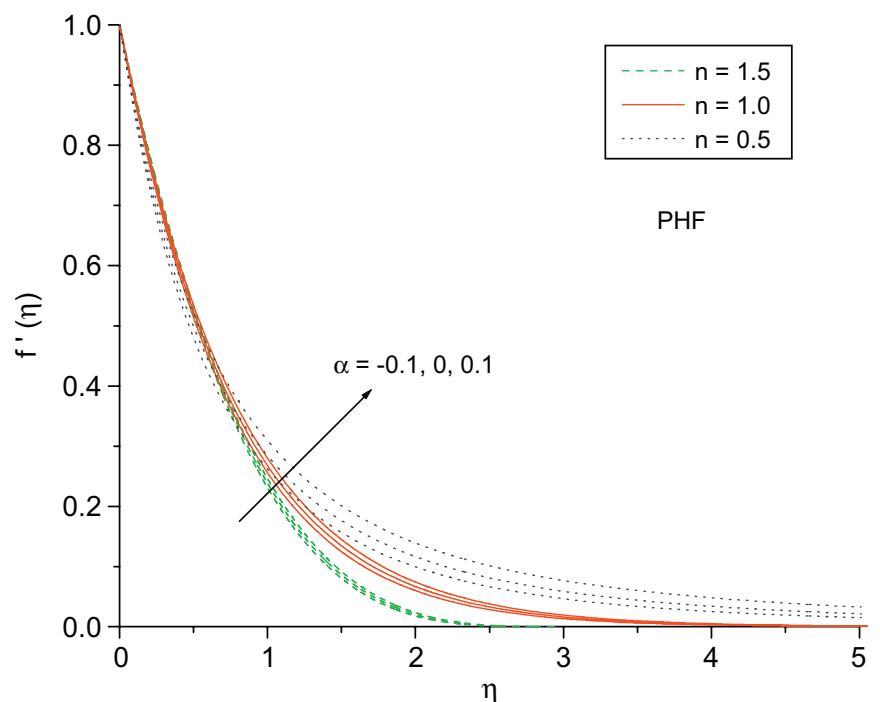

Fig. 6. Effect of space-dependent heat source/sink parameter $\alpha$ on horizontal velocity profiles with $Q=1.0, G r=1.0, \operatorname{Pr}=3.0, \beta=-0.05, \lambda=1.0$ and $\varepsilon=0.1$.

a

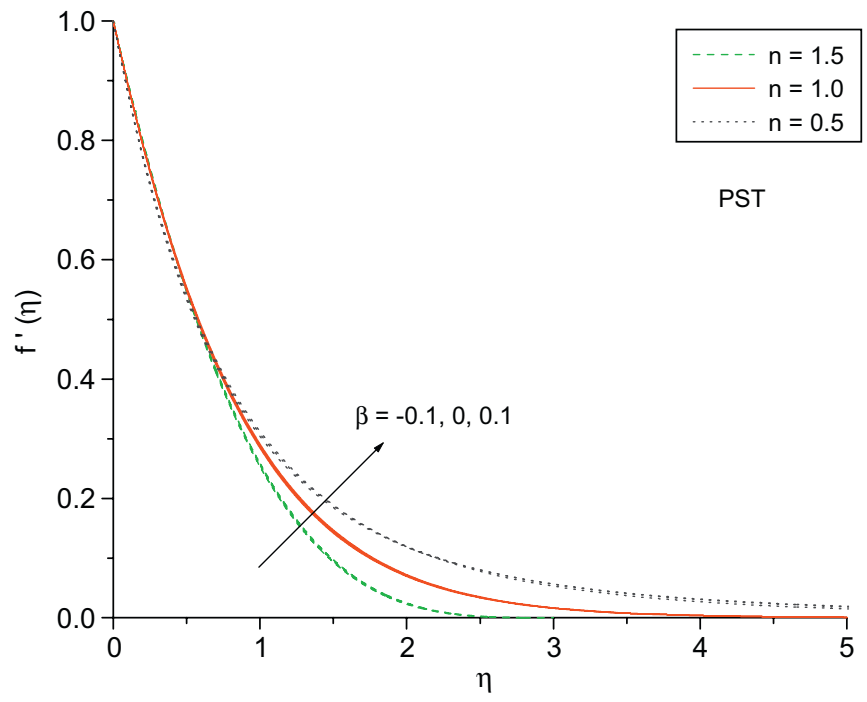

b

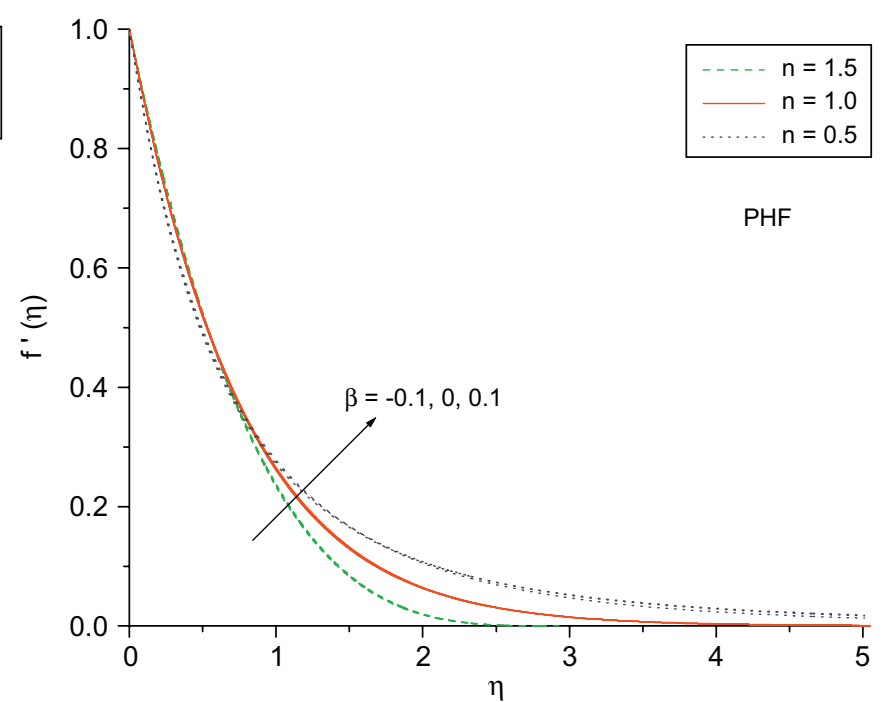

Fig. 7. Effect of temperature-dependent heat source/sink parameter $\beta$ on horizontal velocity profiles with $Q=1.0, \operatorname{Gr}=1.0, \operatorname{Pr}=3.0, \alpha=-0.05, \lambda=1.0$ and $\varepsilon=0.1$. 
a

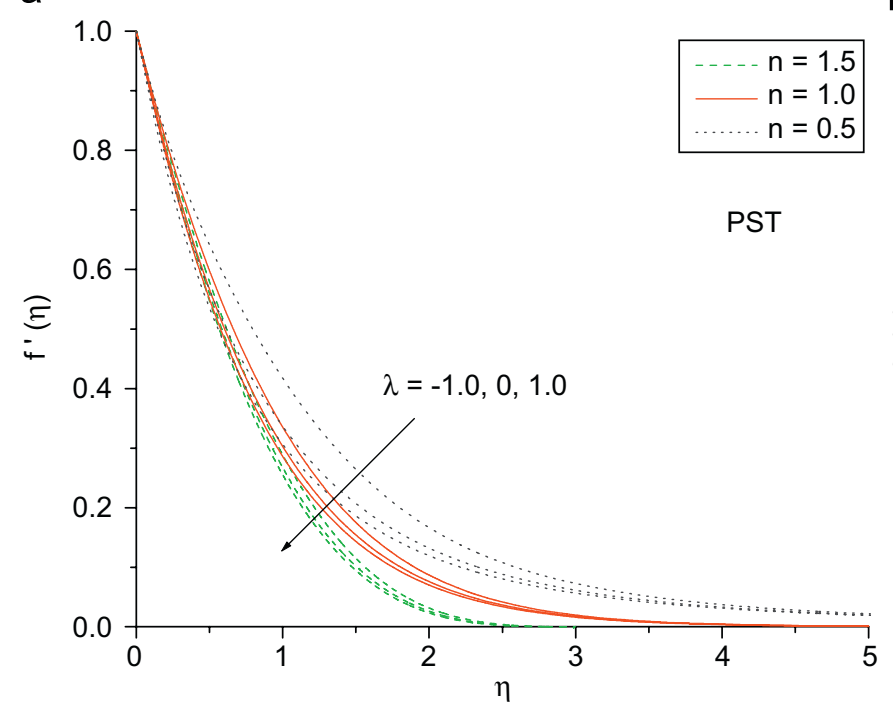

b

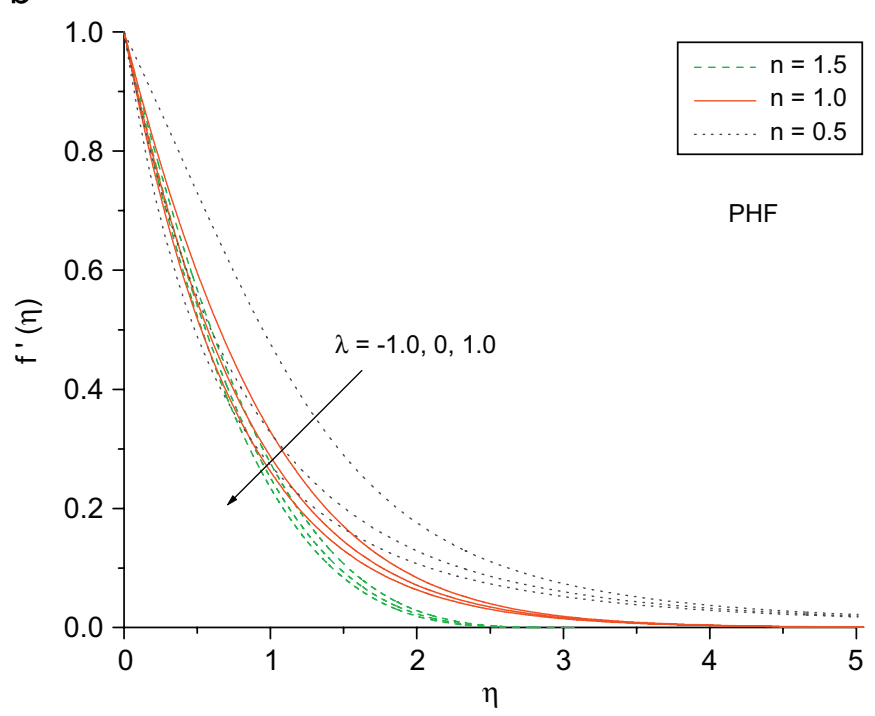

Fig. 8. Effect of wall temperature parameter $\lambda$ on horizontal velocity profiles with $Q=1.0, G r=1.0, \operatorname{Pr}=3.0, \alpha=-0.05, \beta=0.05$ and $\varepsilon=0.1$.

a

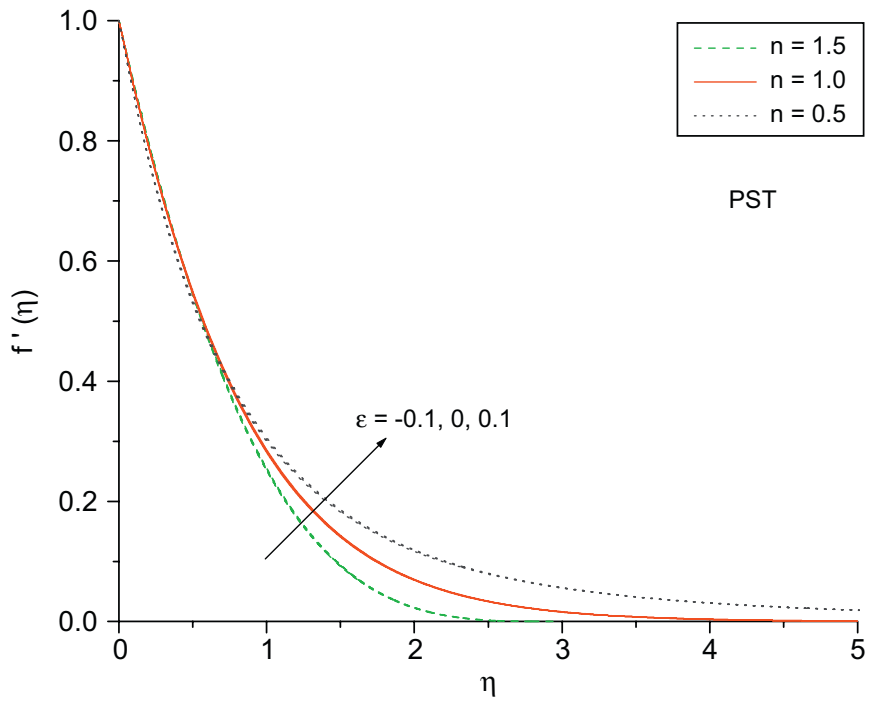

b

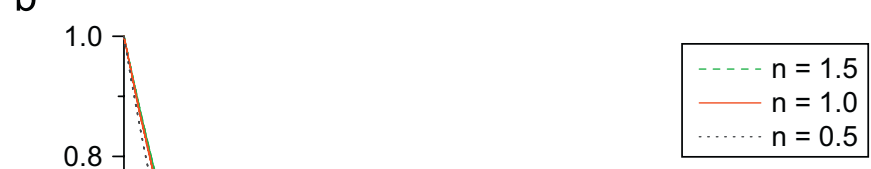

PHF

Fig. 9. Effect of variable thermal conductivity parameter $\varepsilon$ on horizontal velocity profiles with $Q=1.0, G r=1.0, \operatorname{Pr}=3.0, \alpha=-0.05, \beta=-0.05$ and $\lambda=1.0$.

a

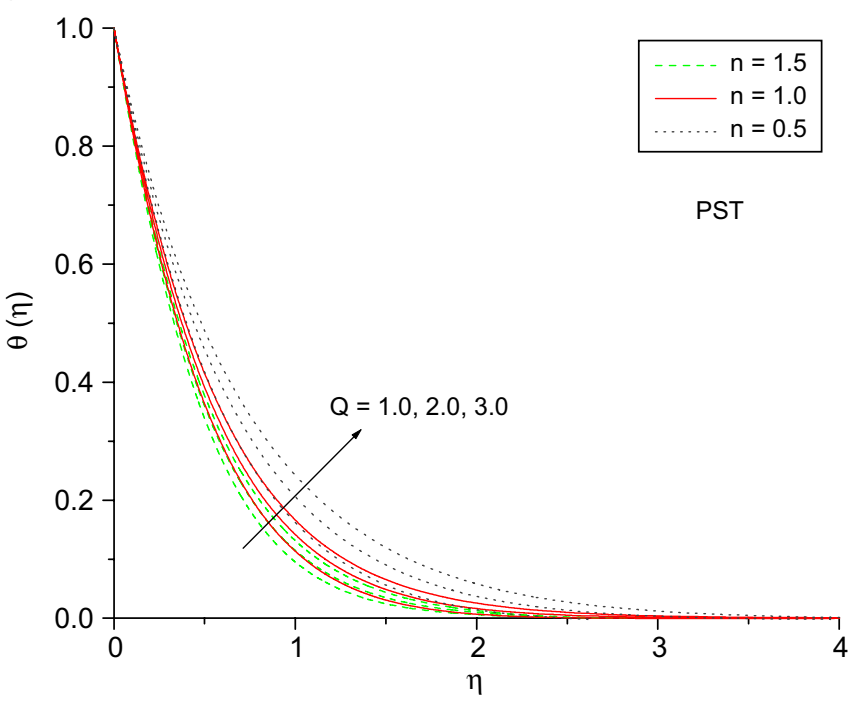

b

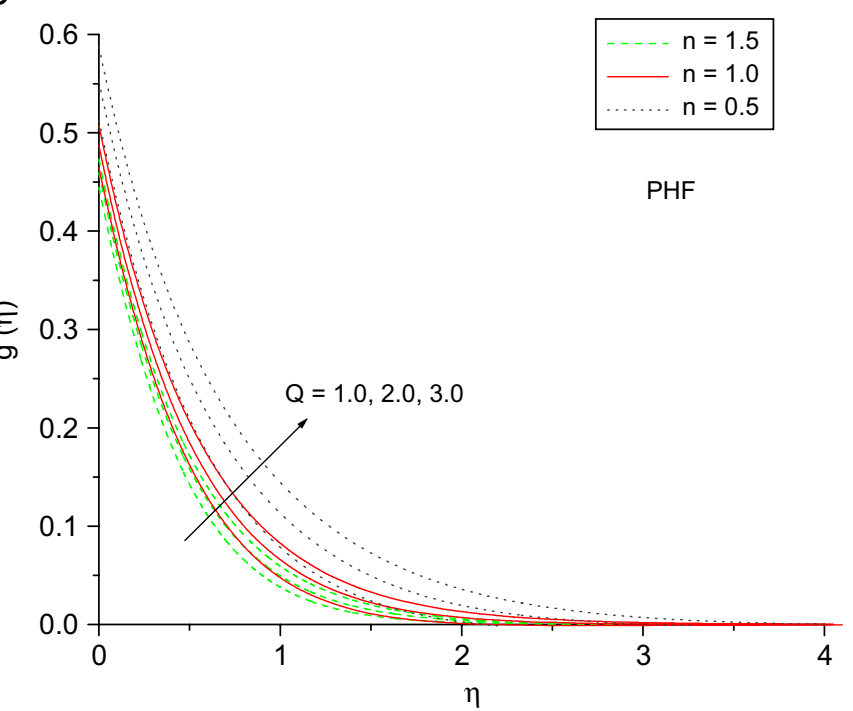

Fig. 10. Effect of $Q$ on temperature profiles with $G r=1.0, \operatorname{Pr}=3.0, \alpha=-0.05, \beta=-0.05, \lambda=1.0$ and $\varepsilon=0.1$. 
a

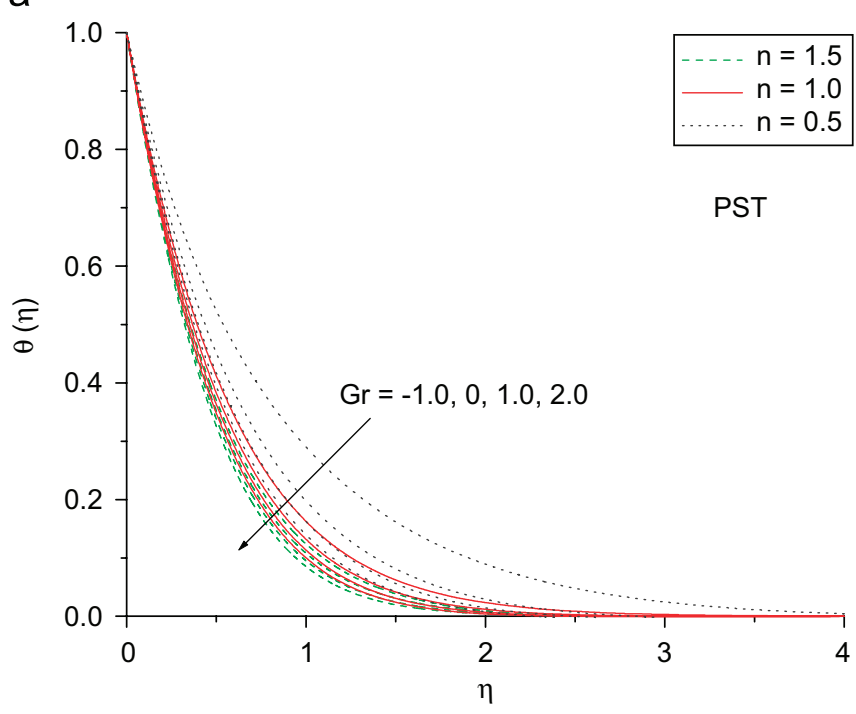

$\mathrm{b}$

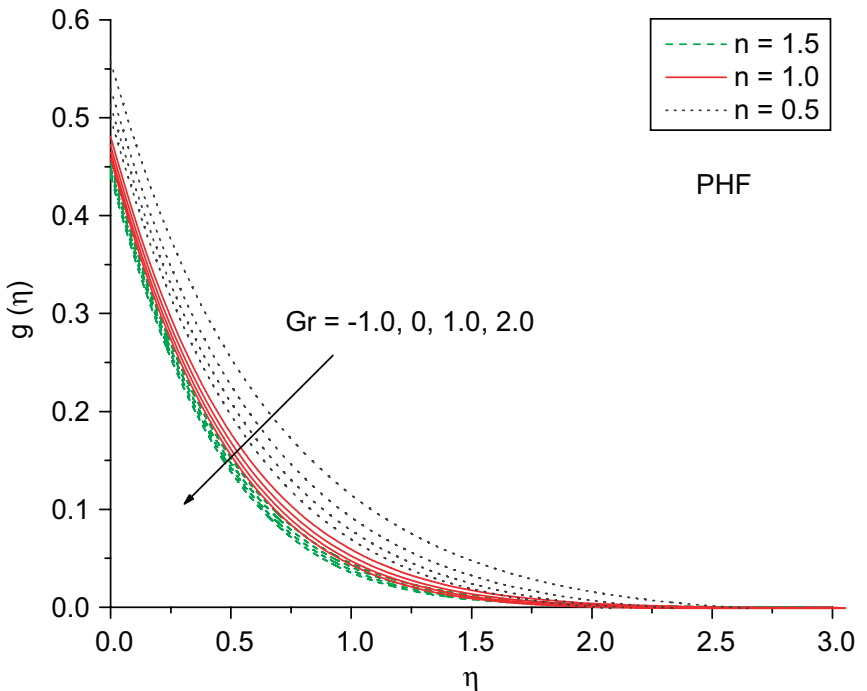

a

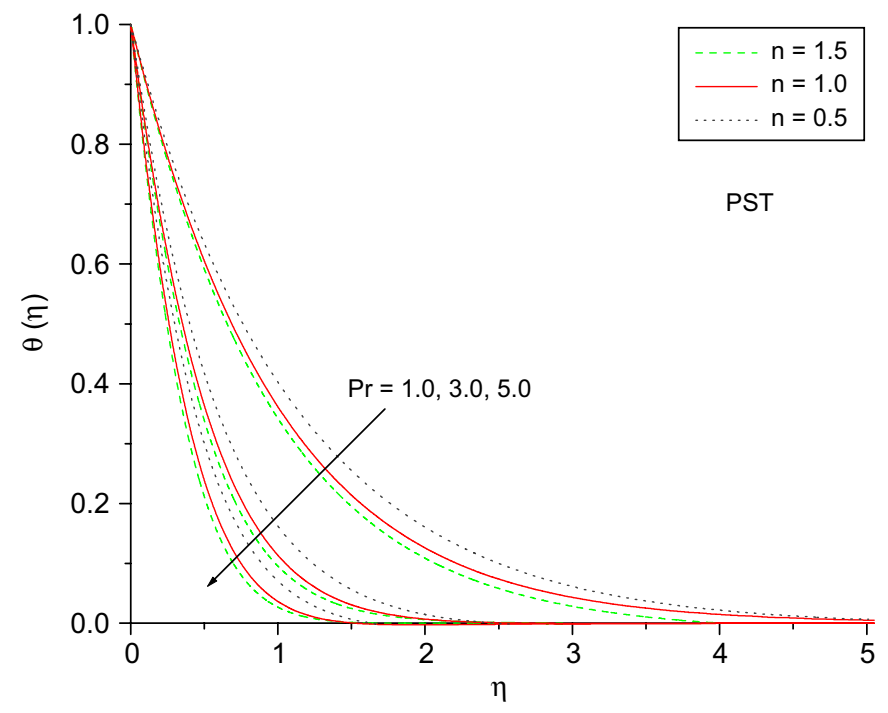

b

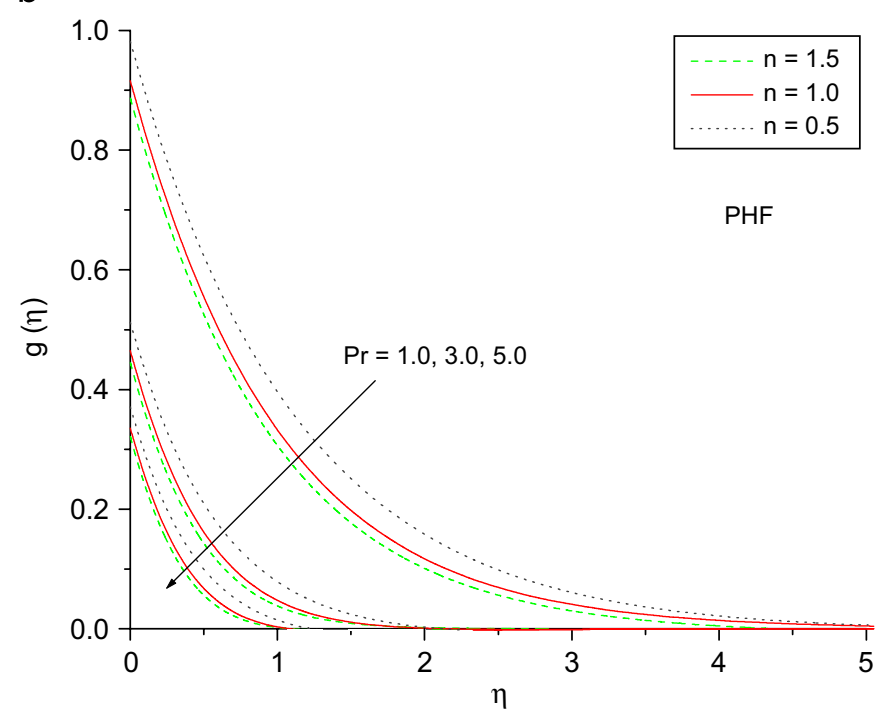

Fig. 12. Effect of $\operatorname{Pr}$ on temperature profiles with $Q=1.0, G r=1.0, \alpha=-0.05, \beta=-0.05, \lambda=1.0$ and $\varepsilon=0.1$.

a

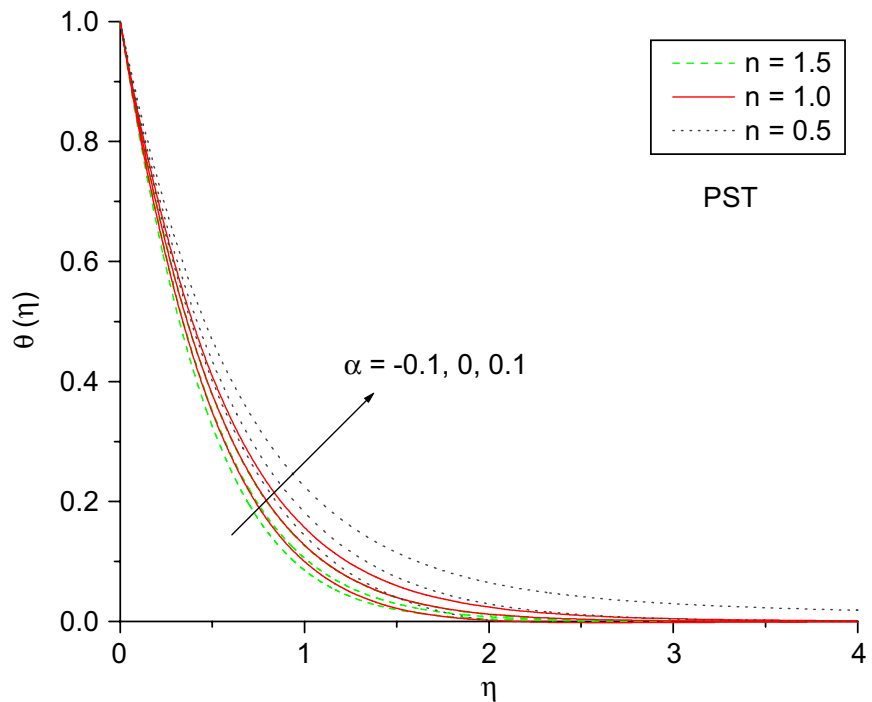

b

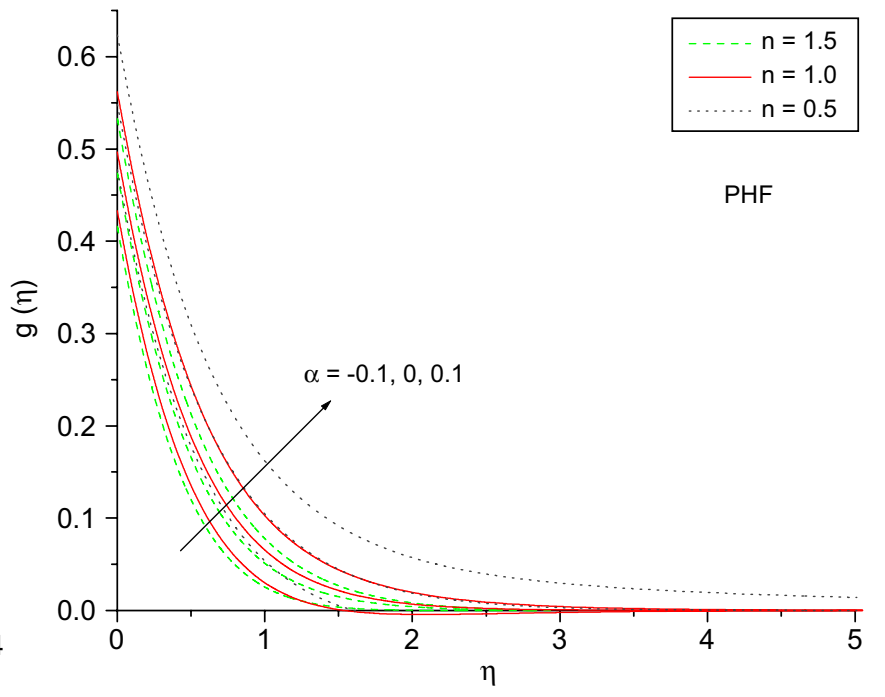

Fig. 13. Effect of $\alpha$ on temperature profiles with $Q=1.0, \operatorname{Pr}=3.0, \mathrm{Gr}=1.0, \beta=-0.05, \lambda=1.0$ and $\varepsilon=0.1$. 

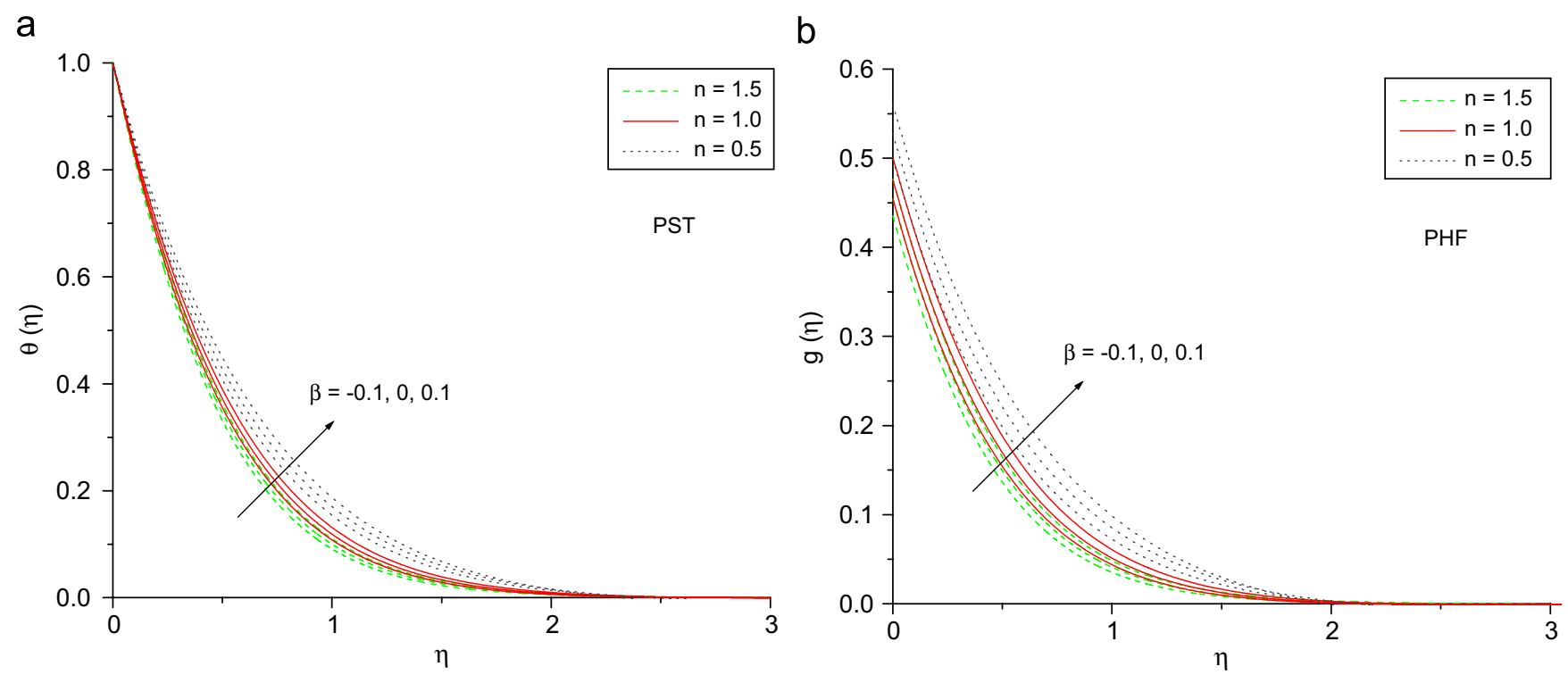

Fig. 14. Effect of $\beta$ on temperature profiles with $Q=1.0, G r=1.0, \operatorname{Pr}=3.0, \alpha=-0.05, \lambda=1.0$ and $\varepsilon=0.1$.

a

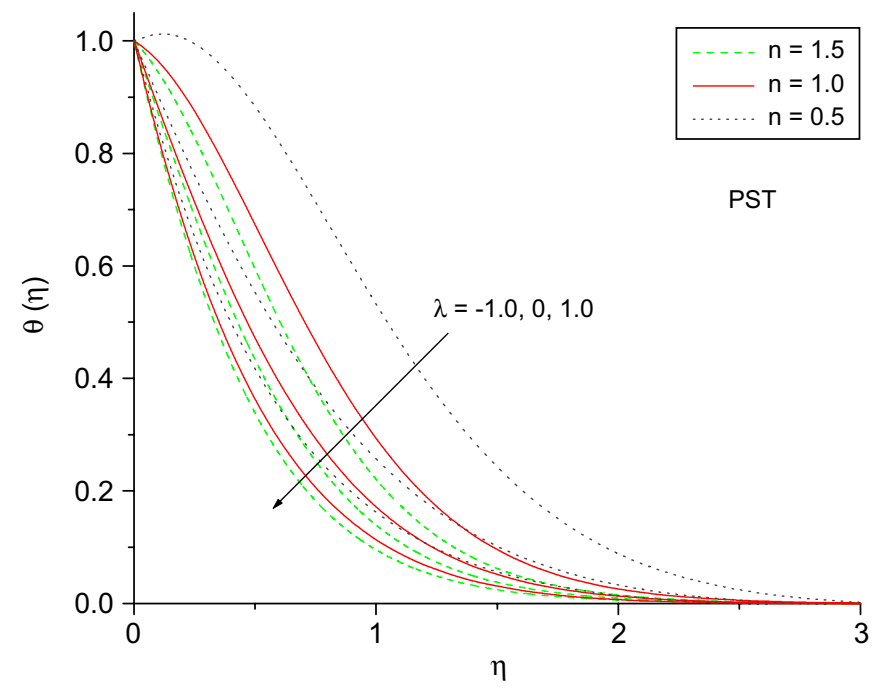

b

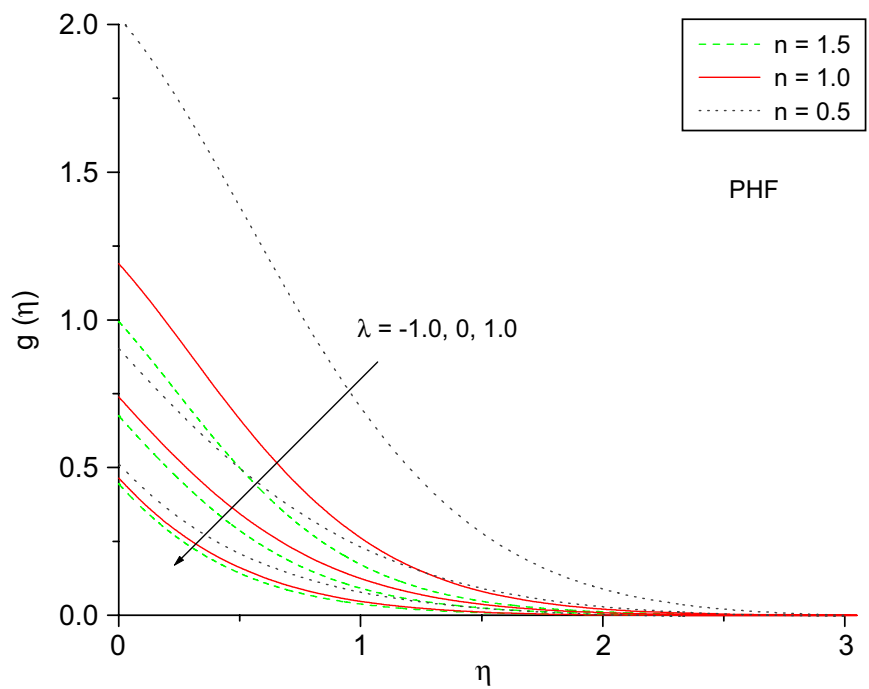

Fig. 15. Effect of $\lambda$ on temperature profiles with $Q=1.0, G r=1.0, \operatorname{Pr}=3.0, \alpha=-0.05, \beta=-0.05$ and $\varepsilon=0.1$.

a

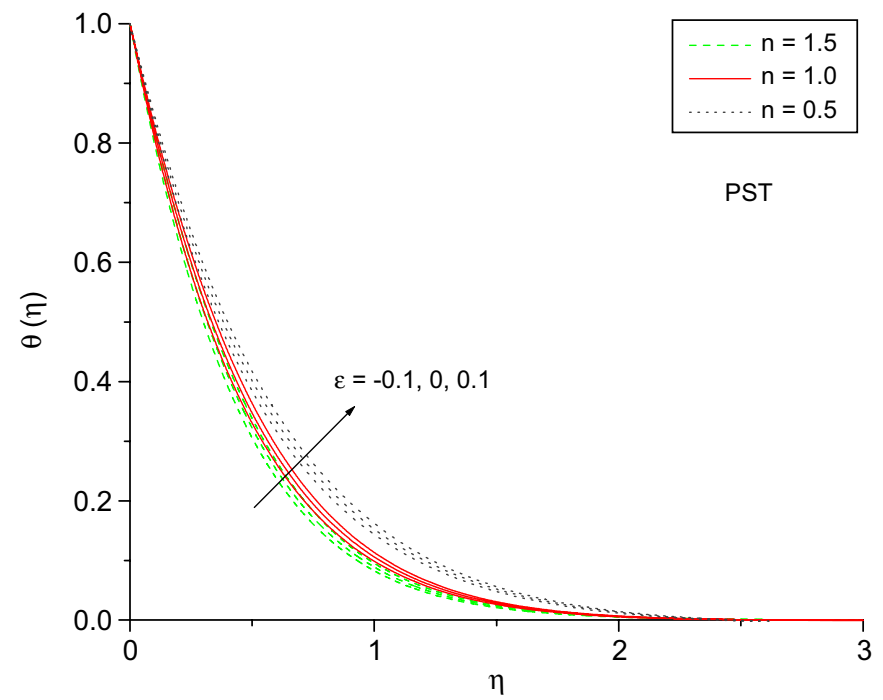

b

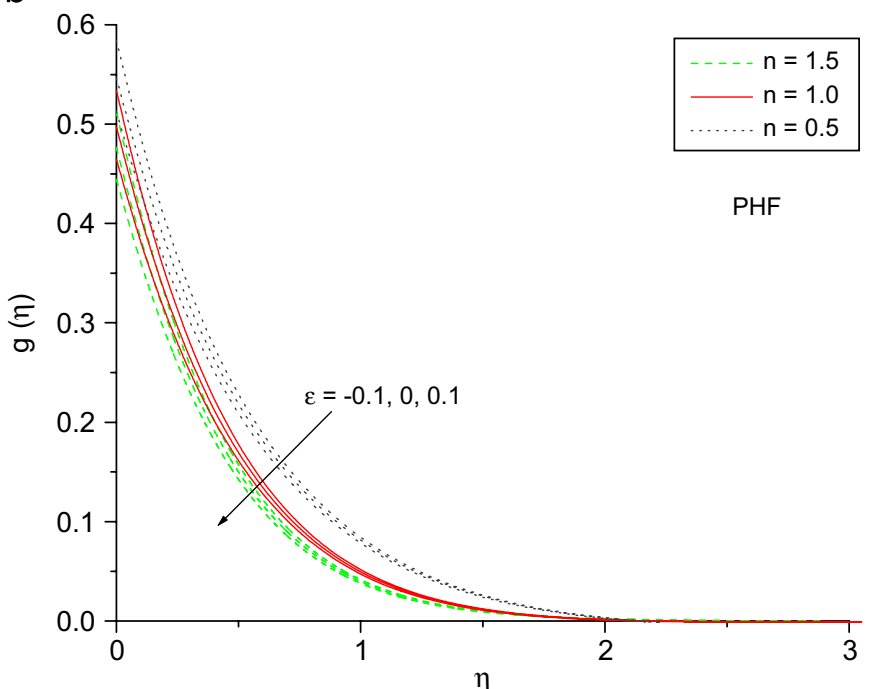

Fig. 16. Effect of $\varepsilon$ on temperature profiles with $Q=1.0, G r=1.0, \operatorname{Pr}=3.0, \alpha=-0.05, \beta=-0.05$ and $\lambda=0.1$. 
Table 1

Values of $-f^{\prime \prime}(0)$ for various values of $Q, G r, \operatorname{Pr}, \varepsilon, \alpha, \beta, \lambda$ and $n$.

\begin{tabular}{|c|c|c|c|c|c|c|}
\hline \multirow[t]{3}{*}{ Parameters } & \multicolumn{6}{|l|}{$-f^{\prime \prime}(0)$} \\
\hline & \multicolumn{2}{|l|}{$n=0.5$} & \multicolumn{2}{|l|}{$n=1.0$} & \multicolumn{2}{|l|}{$n=1.5$} \\
\hline & PST & PHF & PST & PHF & PST & PHF \\
\hline$Q$ & \multicolumn{6}{|c|}{$G r=1.0, \operatorname{Pr}=3.0, \alpha=-0.05, \beta=-0.05, \lambda=1.0, \varepsilon=0.1$} \\
\hline 0.5 & 1.022298 & 1.310817 & 0.940527 & 1.100927 & 0.934178 & 1.049918 \\
\hline 1.0 & 1.353773 & 1.649440 & 1.132142 & 1.286447 & 1.071572 & 1.178431 \\
\hline 2.0 & 1.970829 & 2.260940 & 1.457731 & 1.600323 & 1.296659 & 1.390634 \\
\hline 3.0 & 2.540391 & 2.814144 & 1.734468 & 1.866564 & 1.480831 & 1.565525 \\
\hline Gr & \multicolumn{6}{|c|}{$Q=1.0, \operatorname{Pr}=3.0, \alpha=-0.05, \beta=-0.05, \lambda=1.0, \varepsilon=0.1$} \\
\hline-1.0 & 2.817870 & 2.382901 & 1.725688 & 1.552402 & 1.444026 & 1.337963 \\
\hline-0.5 & 2.351695 & 2.164432 & 1.564745 & 1.481748 & 1.350109 & 1.297191 \\
\hline 0.0 & 1.974419 & 1.974419 & 1.414214 & 1.414214 & 1.257081 & 1.257081 \\
\hline 1.0 & 1.353773 & 1.649440 & 1.132142 & 1.286447 & 1.071572 & 1.178431 \\
\hline 2.0 & 0.863145 & 1.375338 & 0.866959 & 1.166265 & 0.882360 & 1.101271 \\
\hline $\operatorname{Pr}$ & \multicolumn{6}{|c|}{$Q=1.0, G r=1.0, \alpha=-0.05, \beta=-0.05, \lambda=1.0, \varepsilon=0.1$} \\
\hline 1.0 & 1.169400 & 1.182010 & 1.002931 & 1.036294 & 0.967556 & 0.999911 \\
\hline 3.0 & 1.353773 & 1.649440 & 1.132142 & 1.286447 & 1.071572 & 1.178431 \\
\hline 5.0 & 1.442980 & 1.781608 & 1.186145 & 1.343891 & 1.111810 & 1.215066 \\
\hline$\alpha$ & \multicolumn{6}{|c|}{$Q=1.0, G r=1.0, \operatorname{Pr}=3.0, \beta=-0.05, \lambda=1.0, \varepsilon=0.1$} \\
\hline-0.1 & 1.368675 & 1.688094 & 1.139560 & 1.303072 & 1.076139 & 1.188218 \\
\hline 0.0 & 1.338037 & 1.609514 & 1.124555 & 1.269519 & 1.066956 & 1.168502 \\
\hline 0.1 & 1.303333 & 1.524915 & 1.108987 & 1.234716 & 1.057551 & 1.148160 \\
\hline$\beta$ & \multicolumn{6}{|c|}{$Q=1.0, G r=1.0, \operatorname{Pr}=3.0, \alpha=-0.05, \lambda=1.0, \varepsilon=0.1$} \\
\hline-0.1 & 1.360886 & 1.661779 & 1.135645 & 1.290989 & 1.073963 & 1.181130 \\
\hline 0.0 & 1.346384 & 1.636121 & 1.128442 & 1.281491 & 1.069069 & 1.175509 \\
\hline 0.1 & 1.331835 & 1.608617 & 1.120358 & 1.270062 & 1.063612 & 1.168790 \\
\hline$\varepsilon$ & \multicolumn{6}{|c|}{$Q=1.0, G r=1.0, \operatorname{Pr}=3.0, \alpha=-0.05, \beta=-0.05, \lambda=1.0$} \\
\hline-0.1 & 1.378995 & 1.613515 & 1.146736 & 1.270665 & 1.082250 & 1.168370 \\
\hline 0.0 & 1.365921 & 1.631933 & 1.139234 & 1.278815 & 1.076782 & 1.173582 \\
\hline 0.1 & 1.353773 & 1.649440 & 1.132142 & 1.286447 & 1.071572 & 1.178431 \\
\hline$\lambda$ & \multicolumn{6}{|c|}{$Q=1.0, G r=1.0, \operatorname{Pr}=3.0, \alpha=-0.05, \beta=-0.05, \varepsilon=0.1$} \\
\hline-1.0 & 1.028254 & -1.615780 & 1.001388 & -1.403357 & 0.990435 & 0.568982 \\
\hline 0.0 & 1.255005 & 1.319792 & 1.085506 & 1.172656 & 1.041146 & 1.114526 \\
\hline 1.0 & 1.353773 & 1.649440 & 1.132142 & 1.286447 & 1.071572 & 1.178431 \\
\hline
\end{tabular}

From Fig. 5 which illustrates the effect of Prandtl number Pr on the velocity profiles, it is clear that increasing values of $\operatorname{Pr}$ reduces the horizontal velocity profiles in both PST and PHF cases. This observation is true in all three kinds of fluids.

The effect of space-dependent heat source/sink parameter $\alpha$ is to increase the magnitude of horizontal velocity in both PST and PHF cases for all three kinds of fluids. The effect is more pronounced in the case of shear thinning fluids. Same is reiterated in Fig. 6.

The effect of temperature-dependent heat source/sink parameter $\beta$ and the variable thermal conductivity parameter $\varepsilon$ on the horizontal velocity profiles is quite negligible in both PST and PHF cases in the three types of fluids. Small values of $\beta$ and $\varepsilon$ have least effect on horizontal velocity profiles, as can be seen in Figs. 7 and 9 .

The effect of wall temperature parameter $\lambda$ on the flow is shown in Fig. 8 for both the cases of PST and PHF. Increasing value of $\lambda$ results in decreasing the axial velocity causing thinning of boundary layer.

The effect of transverse magnetic field on the heat transfer is depicted in Fig. 10 for both PST and PHF cases. From these plots it is observed that the transverse magnetic field contributes to the thickening of thermal boundary layer. The resistance due to Lorentz force on the flow is responsible for enhancing the temperature in all the three cases: $0<n<1, n=1$ and $n>1$.

Fig. 11 depicts the effect of Grashof number on the heat transfer in PST and PHF cases. It is evident from these plots that increasing value of $\mathrm{Gr}$ results in thinning of the thermal boundary layer associated with an increase in the wall temperature gradient and hence produces an increase in the heat transfer rate.

Fig. 12 shows the effect of Prandtl number on the heat transfer in PST and PHF cases. From these plots it is evident that large values of Prandtl number result in thinning of the thermal boundary layer. This is in contrast to the effects of other parameters, except Gr and $\lambda$ on heat transfer.

Figs. 13 and 14 illustrate the effect of space-dependent heat source/sink parameter $\alpha$ and temperature-dependent heat source/ sink parameter $\beta$, respectively, on the temperature distribution in PST and PHF cases. Before discussing the results we recollect the fact that $\alpha>0, \beta>0$ correspond to internal heat generation and $\alpha<0, \beta<0$ correspond to internal heat absorption. Eq. (6) can be readily seen to be

$q^{\prime \prime \prime}=\frac{\rho k_{\infty} U_{0} \Delta t}{L K}(1+\varepsilon T)\left(A^{*} f^{\prime}+B^{*} T\right)$,

where use has been made of the definition of dimensionless variables. The heat generation/absorption clearly depends on the axial flow and also on the boundary layer temperature $T$. It is the cumulative influence of the space-dependent and temperature-dependent heat source/sink parameter that determines the extent to which the temperature falls or rises in the boundary layer region. From the plots it is clear that the energy is released for increasing values of $\alpha$ and $\beta>0$, and this causes the magnitude of temperature to increase both in PST and PHF cases, where as energy is absorbed for 
Table 2

Values of $-\theta^{\prime}(0)$ and $g(0)$ for various values of $Q, G r, P r, \varepsilon, \alpha, \beta, \lambda$ and $n$.

\begin{tabular}{|c|c|c|c|c|c|c|}
\hline \multirow[t]{2}{*}{ Parameters } & \multicolumn{2}{|l|}{$n=0.5$} & \multicolumn{2}{|l|}{$n=1.0$} & \multicolumn{2}{|l|}{$n=1.5$} \\
\hline & $-\theta^{\prime}(0)$ & $g(0)$ & $-\theta^{\prime}(0)$ & $g(0)$ & $-\theta^{\prime}(0)$ & $g(0)$ \\
\hline$Q$ & \multicolumn{6}{|c|}{$G r=1.0, \operatorname{Pr}=3.0, \alpha=-0.05, \beta=-0.05, \lambda=1.0, \varepsilon=0.1$} \\
\hline 0.5 & 1.771369 & 0.490516 & 1.899539 & 0.451718 & 1.963695 & 0.435895 \\
\hline 1.0 & 1.709040 & 0.512449 & 1.855221 & 0.464748 & 1.929407 & 0.444739 \\
\hline 2.0 & 1.604343 & 0.551856 & 1.780755 & 0.487366 & 1.872201 & 0.460080 \\
\hline 3.0 & 1.518591 & 0.587306 & 1.718663 & 0.507445 & 1.825321 & 0.473257 \\
\hline$G r$ & \multicolumn{6}{|c|}{$Q=1.0, \operatorname{Pr}=3.0, \alpha=-0.05, \beta=-0.05, \lambda=1.0, \varepsilon=0.1$} \\
\hline-1.0 & 1.429430 & 0.557233 & 1.724763 & 0.480711 & 1.841978 & 0.454480 \\
\hline-0.5 & 1.544340 & 0.541720 & 1.766472 & 0.476058 & 1.866152 & 0.451822 \\
\hline 0.0 & 1.613049 & 0.530015 & 1.800241 & 0.471917 & 1.888819 & 0.449325 \\
\hline 1.0 & 1.709040 & 0.512449 & 1.855221 & 0.464748 & 1.929407 & 0.444739 \\
\hline 2.0 & 1.778170 & 0.499384 & 1.900383 & 0.458639 & 1.929427 & 0.440609 \\
\hline $\operatorname{Pr}$ & \multicolumn{6}{|c|}{$Q=1.0, G r=1.0, \alpha=-0.05, \beta=-0.05, \lambda=1.0, \varepsilon=0.1$} \\
\hline 1.0 & 0.925793 & 0.982031 & 0.991087 & 0.915869 & 1.023301 & 0.886817 \\
\hline 3.0 & 1.709040 & 0.512449 & 1.855221 & 0.464748 & 1.929407 & 0.444739 \\
\hline 5.0 & 2.269228 & 0.370772 & 2.469840 & 0.335353 & 2.573138 & 0.320879 \\
\hline$\alpha$ & \multicolumn{6}{|c|}{$Q=1.0, G r=1.0, \operatorname{Pr}=3.0, \beta=-0.05, \lambda=1.0, \varepsilon=0.1$} \\
\hline-0.1 & 1.766488 & 0.477465 & 1.911486 & 0.433198 & 1.983285 & 0.415916 \\
\hline 0.0 & 1.650330 & 0.548341 & 1.798328 & 0.496719 & 1.875178 & 0.473823 \\
\hline 0.1 & 1.528297 & 0.623335 & 1.682688 & 0.561982 & 1.765605 & 0.532837 \\
\hline$\beta$ & \multicolumn{6}{|c|}{$Q=1.0, G r=1.0, \operatorname{Pr}=3.0, \alpha=-0.05, \lambda=1.0, \varepsilon=0.1$} \\
\hline-0.1 & 1.753444 & 0.498819 & 1.896008 & 0.454429 & 1.968660 & 0.435656 \\
\hline 0.0 & 1.663331 & 0.527250 & 1.813331 & 0.475877 & 1.889197 & 0.454472 \\
\hline 0.1 & 1.568473 & 0.559962 & 1.725826 & 0.501073 & 1.805463 & 0.476323 \\
\hline$\varepsilon$ & \multicolumn{6}{|c|}{$Q=1.0, G r=1.0, \operatorname{Pr}=3.0, \alpha=-0.05, \beta=-0.05, \lambda=1.0$} \\
\hline-0.1 & 1.953533 & 0.584350 & 2.124963 & 0.534150 & 2.212072 & 0.512619 \\
\hline 0.0 & 1.819890 & 0.546538 & 1.977567 & 0.497478 & 2.057639 & 0.476676 \\
\hline 0.1 & 1.709040 & 0.512449 & 1.855221 & 0.464748 & 1.929407 & 0.444739 \\
\hline$\lambda$ & \multicolumn{6}{|c|}{$Q=1.0, G r=1.0, \operatorname{Pr}=3.0, \alpha=-0.05, \beta=-0.05, \varepsilon=0.1$} \\
\hline-1.0 & -0.271864 & 15.32029 & 0.239294 & 7.112590 & 0.441667 & 2.366320 \\
\hline 0.0 & 0.999082 & 0.902991 & 1.198510 & 0.739193 & 1.301570 & 0.675120 \\
\hline 1.0 & 1.709040 & 0.512449 & 1.855221 & 0.464748 & 1.929407 & 0.444739 \\
\hline
\end{tabular}

decreasing values of $\alpha, \beta<0$ resulting in temperature dropping significantly near the boundary layer. In any case it is observed in all these plots that there is a transfer of heat from the boundary layer region to the sheet for some negative values of $\alpha$.

The effect of wall temperature parameter $\lambda$ on the heat transfer is typical and is as in Grubka and Bobba [4]. Fig. 15 shows the effect of $\lambda$ for PST and PHF cases for all three types of fluids. It is observed in both PST and PHF cases that above some critical negative value $\lambda_{c}$, the increasing value of $\lambda$ results in decreasing the magnitude of temperature. There will be transfer of heat from sheet to the fluid for $\lambda>\lambda_{\mathrm{c}}$. Below this critical value the effect of $\lambda$ is opposite, i.e., if $\lambda<\lambda_{\mathrm{c}}$ the heat diffuses from the fluid to sheet. This case is of least interest because the present investigation eyes on cooling of the sheet. Hence in Fig. 15 the values of $\lambda$ are chosen above the critical value $\lambda_{\mathrm{c}}$. When $\lambda=\lambda_{\mathrm{c}}$, there is no heat transfer between the stretching surface and the ambient fluid for both the cases of PST and PHF. The said effect is observed for all values of $n$ but with different critical values of $\lambda$.

The effect of variable thermal conductivity parameter $\varepsilon$ on the heat transfer is shown in Fig. 16 for PST and PHF cases. It is observed from these plots that in the PST case the increasing values of $\varepsilon$ results in increasing the magnitude of temperature causing thermal boundary layer thickening. This concurs with the results reported by Chiam [6,7]. In the PHF case an opposite effect is observed (see also [25]). It is also found that the wall temperature gradient $g(0)$ becomes steep for not-so-small values of $\varepsilon$.

We now move over to a discussion on the skin friction at the stretching a sheet. It is important to note here that the momentum and heat transfer equations are mutually coupled (see Eqs. 17, 19 and 21) and hence the thermal boundary conditions have an influence on skin friction in the vertical stretching sheet problem unlike in the case of the horizontal stretching sheet one. The values of $-f^{\prime \prime}(0)$ in case of PST and PHF are listed in Table 1 for various values of influencing parameters. We see from the table that the skin friction is highest in the case of dilatant liquids in comparison with those of pseudo-plastics and Newtonian ones. Furthermore, skin friction increases with increase in the values of $Q, \operatorname{Pr}$ and $\lambda$. The Grashof number has an opposite effect to that of $Q, \operatorname{Pr}$ and $\lambda$. The effect of $\varepsilon$ is similar to that of $G r$ and so is the effect of $\alpha$ and $\beta$. In general we notice that for all parameter combinations the following is true:

\section{$\left[-f^{\prime \prime}(0)\right]_{\mathrm{PST}}<\left[-f^{\prime \prime}(0)\right]_{\mathrm{PHF}}$.}

We note that the temperature is fixed in the case of PST and hence we calculate the flux and vice versa in the case of PHF. It is inappropriate therefore to compare $-\theta^{\prime}(0)$ and $g(0)$. The most appropriate thing would be to compare the local Nusselt numbers in the two cases. The values of wall temperature gradient $-\theta^{\prime}(0)$ in case of PST and wall temperature $g(0)$ in case of PHF are tabulated for a range of values of the physical parameters in Table 2. Analyzing these tables we infer that the effect of increasing values of all the parameters, except $\mathrm{Pr}, \mathrm{Gr}$ and $\lambda$, is to increase the values of $-\theta^{\prime}(0)$ and $g(0)$ in pseudo-plastic, Newtonian and dilatant fluids. 


\section{Conclusions}

Some of the important findings of the paper are:

1. The effects of Chandrasekhar number $Q$, Prandtl number Pr and wall temperature parameter $\lambda$ are to oppose the flow and that of space-dependent heat source/sink parameter $\alpha$ is to assist the flow. The effects of temperature-dependent heat source/sink parameter $\beta$ and the variable thermal conductivity parameter $\varepsilon$ on the flow are quite negligible.

2. The buoyancy parameter $G r$ has a considerable influence in controlling the flow. The effect of $G r$ is to increase the momentum boundary layer thickness and to decrease the thermal boundary layer thickness.

3. The individual and collective effects of increasing $Q, \alpha$, and $\beta$ are to increase the magnitude of heat transfer. An opposite effect is observed for increasing values of $\operatorname{Pr}$ and $\lambda$.

4. The variable thermal conductivity parameter $\varepsilon$ increases the magnitude of temperature in PST case and decreases in PHF case. The wall temperature in case of PHF is dependent on the value of $\varepsilon$ and exhibits steepening for high values of $\varepsilon$.

5. The magnitude of $\lambda$ dictates the direction of heat transfer in both PST and PHF cases.

6. In the limiting case of $G r=0$ one can obtain the results of the horizontal stretching sheet.

7. For effective cooling of the stretching sheet, space- and temperature-dependent heat sinks are desirable.

\section{Acknowledgments}

The authors are thankful to the referee for the most useful comments that significantly improved our paper and to the Department of Science and Technology, New Delhi, for providing financial support to carryout this work under the major research project (Grant no. SR/S4/MS: 198/03). The work of PGS was supported by the UGC Centre for Advanced Studies. Bangalore University, Bangalore.

\section{References}

[1] L.J. Crane, Flow past a stretching sheet, ZAMP 21 (1970) 645-647.

[2] P.S. Gupta, A.S. Gupta, Heat and mass transfer on a stretching sheet with suction or blowing, Can. J. Chem. Eng. 55 (1977) 744-746.

[3] C.K. Chen, M.I. Char, Heat transfer of a continuous stretching surface with suction or blowing, J. Math. Anal. Appl. 135 (1988) 568-580.

[4] L.J. Grubka, K.M. Bobba, Heat transfer characteristics of a continuous stretching surface with variable temperature, ASME J. Heat Transfer 107 (1985) 248-250.

[5] T.C. Chiam, Magnetohydrodynamic heat transfer over a non-isothermal stretching sheet, Acta Mech. 122 (1997) 169-179.

[6] T.C. Chiam, Heat transfer with variable conductivity in a stagnation-point flow towards a stretching sheet, Int. Commun. Heat Mass Transfer 23 (1996) 239-248.

[7] T.C. Chiam, Heat transfer in a fluid with variable thermal conductivity over a linearly stretching sheet, Acta Mech. 129 (1998) 63-72.
[8] K. Vajravelu, D. Rollins, Heat transfer in electrically conducting fluid over a stretching surface, Int. J. Non-Linear Mech. 27 (2) (1992) 265-277.

[9] E.M. Abo-Eldahab, M.A. El Aziz, Blowing/suction effect on hydromagnetic heat transfer by mixed convection from an inclined continuously stretching surface with internal heat generation/absorption, Int. J. Therm. Sci. 43 (2004) 709-719.

[10] K. Vajravelu, J. Nayfeh, Convective heat transfer at a stretching sheet, Acta Mech. 96 (1993) 47-54.

[11] R.S.R. Gorla, D.E. Abboud, A. Sarmah, Magnetohydrodynamic flow over a vertical stretching surface with suction and blowing, Heat Mass Transfer 34 (1998) 121-125.

[12] C.-H. Chen, Laminar mixed convection adjacent to vertical continuously stretching sheets, Heat Mass Transfer 33 (1998) 471-476.

[13] C.-H. Chen, Mixed convection cooling of a heated, continuously stretching surface, Heat Mass Transfer 36 (2000) 79-86.

[14] A.A. Afify, MHD free convective flow and mass transfer over a stretching sheet with chemical reaction, Heat Mass Transfer 40 (2004) 495-500.

[15] M.K. Partha, P.V.S.N. Murthy, G.P. Rajasekhar, Effect of viscous dissipation on the mixed convection heat transfer from an exponentially stretching surface, Heat Mass Transfer 41 (2005) 360-366.

[16] H.I. Andersson, K.H. Bech, B.S. Dandapat, Magnetohydrodynamic flow of a power-law fluid over a stretching sheet, Int. J. Non-Linear Mech. 27 (6) (1992) 929-936.

[17] I.A. Hassanien, A.A. Abdullah, R.S. Gorla, Flow and heat transfer in a power-law fluid over a non-isothermal stretching sheet, Math. Comput. Modelling 28 (9) (1998) 105-116.

[18] S.J. Liao, On the analytic solution of magnetohydrodynamic flows of nonNewtonian fluids over a stretching sheet, J. Fluid Mech. 488 (2003) 189-212.

[19] R. Cortell, A note on magnetohydrodynamic flow of a power-law fluid over a stretching sheet, Appl. Math. Comput. 168 (2005) 557-566.

[20] K.R. Rajagopal, T.Y. Na, A.S. Gupta, Flow of a visco-elastic fluid over a stretching sheet, Rheol. Acta 23 (1984) 213-215.

[21] P.G. Siddheshwar, U.S. Mahabaleshwar, Effect of radiation and heat source on MHD flow of a viscoelastic liquid and heat transfer over a stretching sheet, Int. J. Non-Linear Mech. 40 (2005) 807-820.

[22] R. Cortell, Flow and heat transfer of an electrically conducing fluid of second grade over a stretching sheet subject to suction and to a transverse magnetic field, Int. J. Heat Mass Transfer 49 (2006) 1851-1856.

[23] H.I. Andersson, MHD flow of a viscoelastic fluid past a stretching surface, Acta Mech. 95 (1992) 227-230.

[24] M.S. Abel, P.G. Siddheshwar, M.M. Nandeppanavar, Heat transfer in a viscoelastic fluid past a stretching sheet with non-uniform heat source, Int. J. Heat Mass Transfer 50 (2007) 960-966.

[25] M.S. Abel, N. Mahesha, Heat transfer in MHD viscoelastic fluid flow over stretching sheet with variable thermal conductivity, non-uniform heat source and radiation, Appl. Math. Modelling 32 (2008) 1965-1983.

[26] A. Subhas, K.V. Prasad, A. Mahaboob, Buoyancy force and thermal radiation effects in MHD boundary layer viscoelastic flow over continuously moving stretching surface, Int. J. Therm. Sci. 44 (2005) 465-476.

[27] R. Cortell, Viscous flow and heat transfer over a nonlinearly stretching sheet, Appl. Math. Comput. 184 (2) (2007) 864-873.

[28] R. Cortell, Effects of viscous dissipation and radiation on the thermal boundary layer over a nonlinearly stretching sheet, Phys. Lett. A 372 (5) (2008) 631-636.

[29] R. Cortell, Similarity solutions for flow and heat transfer of a quiescent fluid over a nonlinearly stretching sheet, J. Mater. Process. Technol. 203 (1-3) (2008) $176-183$.

[30] R.B. Bird, W.E. Stewart, E.N. Lightfoot, Transport Phenomena, Wiley, New York 1960.

[31] S.D. Conte, C. de Boor, Elementary Numerical Analysis, McGraw-Hill, New York 1972.

[32] T. Cebeci, P. Bradshaw, Physical and Computational Aspects of Convective Heat Transfer, Springer, New York, 1984

[33] P.G. Siddheshwar, Thermorheological effect on magneto convection in weak electrically conducting fluids under $1 \mathrm{~g}$ or $\mu \mathrm{g}$, Pramana - J. Physics 62 (1) (2004) $61-68$ 